\title{
Hsc70 Ameliorates the Vesicle Recycling Defects Caused by Excess $\alpha$-Synuclein at Synapses
}

\author{
(1) Susan M. L. Banks, ${ }^{1 *}$ ¿Audrey T. Medeiros, ${ }^{1{ }^{*}}$ Molly McQuillan, ${ }^{1}$ David J. Busch, ${ }^{2}$ Ana Sofia \\ Ibarraran-Viniegra, ${ }^{1}{ }^{\circledR}$ Rui Sousa, ${ }^{3}{ }^{\circledR}$ Eileen M. Lafer, ${ }^{3}$ and ${ }^{\circledR J e n n i f e r ~ R . ~ M o r g a n ~}{ }^{1}$
}

https://doi.org/10.1523/ENEURO.0448-19.2020

${ }^{1}$ The Eugene Bell Center for Regenerative Biology and Tissue Engineering Marine Biological Laboratory, Woods Hole, MA 02543, ${ }^{2}$ Department of Biomedical Engineering, The University of Texas at Austin, Austin, TX 78712, and ${ }^{3}$ Department of Biochemistry and Structural Biology and Center for Biomedical Neuroscience, the University of Texas Health Science Center at San Antonio, San Antonio, TX 79229

\begin{abstract}
$\alpha$-Synuclein overexpression and aggregation are linked to Parkinson's disease (PD), dementia with Lewy bodies (DLB), and several other neurodegenerative disorders. In addition to effects in the cell body, $\alpha$-synuclein accumulation occurs at presynapses where the protein is normally localized. While it is generally agreed that excess $\alpha$-synuclein impairs synaptic vesicle trafficking, the underlying mechanisms are unknown. We show here that acute introduction of excess human $\alpha$-synuclein at a classic vertebrate synapse, the lamprey reticulospinal (RS) synapse, selectively impaired the uncoating of clathrin-coated vesicles (CCVs) during synaptic vesicle recycling, leading to an increase in endocytic intermediates and a severe depletion of synaptic vesicles. Furthermore, human $\alpha$-synuclein and lamprey $\gamma$-synuclein both interact in vitro with $\mathrm{Hsc} 70$, the chaperone protein that uncoats CCVs at synapses. After introducing excess $\alpha$-synuclein, Hsc70 availability was reduced at stimulated synapses, suggesting Hsc70 sequestration as a possible mechanism underlying the synaptic vesicle trafficking defects. In support of this hypothesis, increasing the levels of exogenous Hsc70 along with $\alpha$-synuclein ameliorated the CCV uncoating and vesicle recycling defects. These experiments identify a reduction in Hsc70 availability at synapses, and consequently its function, as the mechanism by which $\alpha$-synuclein induces synaptic vesicle recycling defects. To our knowledge, this is the first report of a viable chaperone-based strategy for reversing the synaptic vesicle trafficking defects associated with excess $\alpha$-synuclein, which may be of value for improving synaptic function in PD and other synuclein-linked diseases.
\end{abstract}

Key words: auxilin; chaperone; clathrin; clathrin-coated vesicles; endocytosis; lamprey

\section{Significance Statement}

Synaptic defects caused by $\alpha$-synuclein overexpression are linked to cognitive deficits in Parkinson's disease (PD) and other diseases. However, the mechanisms by which excess $\alpha$-synuclein impairs synaptic vesicle trafficking are unknown. Data presented here demonstrate that acute introduction of excess $\alpha$-synuclein at a classical vertebrate synapse inhibits clathrin-coated vesicle (CCV) uncoating, leading to impaired vesicle recycling. Furthermore, increasing $\alpha$-synuclein also reduced synaptic levels of Hsc70, the clathrin uncoating chaperone protein, indicating sequestration of $\mathrm{Hsc70}$ as a possible underlying mechanism. Subsequently increasing exogenous Hsc70 restored CCV uncoating and vesicle recycling. This study identifies a novel molecular mechanism underlying the $\alpha$-synuclein-induced synaptic defects and presents one viable strategy for reversing them. 


\section{Introduction}

$\alpha$-Synuclein is a presynaptic protein whose aberrant aggregation causes neurodegeneration in Parkinson's disease (PD), dementia with Lewy bodies (DLB), and several variants of Alzheimer's disease (Singleton et al., 2003; Lee and Trojanowski, 2006; Cookson and van der Brug, 2008; Ingelsson, 2016). Inherited forms of PD are linked to multiplication of the $\alpha$-synuclein gene (SNCA), as well as several point mutations (e.g., A30P, E46K, A53T), which result in atypical aggregation of $\alpha$-synuclein protein throughout neurons (Singleton et al., 2003; Lee and Trojanowski, 2006). $\alpha$-Synuclein aggregation causes synaptic dysfunction, mitochondrial damage, and axonal transport deficits (Ingelsson, 2016). Though the mechanisms of $\alpha$-synuclein toxicity are beginning to emerge, particularly with respect to events in the soma, much less is known about how increased $\alpha$-synuclein levels affect synapses where the protein normally functions.

Under physiologic conditions, $\alpha$-synuclein participates in synaptic vesicle trafficking via its established roles in vesicle clustering/reclustering (Nemani et al., 2010; Atias et al., 2019), SNARE complex assembly (Burré et al., 2010), vesicle fusion (Bendor et al., 2013; Logan et al., 2017, Sulzer and Edwards, 2019), and synaptic vesicle trafficking/recycling (Cabin et al., 2002; Greten-Harrison et al., 2010; Vargas et al., 2014; Wang et al., 2014; Sun et al., 2019). In contrast, much less is known about the impacts of excess $\alpha$-synuclein at synapses, which occurs during disease pathologies. Acutely increasing $\alpha$-synuclein at several vertebrate synapses leads to an inhibition of synaptic vesicle recycling (Busch et al., 2014; Xu et al., 2016; Eguchi et al., 2017). Overexpression of $\alpha$-synuclein in animal

Received October 28, 2019; accepted January 3, 2020; First published January 15, 2020

The authors declare no competing financial interests.

Author contributions: S.M.L.B., A.T.M., R.S., E.M.L., and J.R.M. designed research; S.M.L.B., A.T.M., M.M., D.J.B., A.S.I.-V., R.S., E.M.L., and J.R.M. performed research; S.M.L.B., A.T.M., M.M., R.S., E.M.L., and J.R.M. analyzed data; S.M.L.B., A.T.M., M.M., D.J.B., A.S.I.-V., R.S., E.M.L., and J.R.M. wrote the paper; A.T.M. contributed unpublished reagents/analytic tools.

This work was supported by Department of Health and Human Services/ National Institutes of Health (HHS/NIH) National Institute of Neurological Disorders and Stroke/National Institute on Aging Grant R01NS078165 (to J.R.M.) and $\mathrm{HHS} / \mathrm{NIH}$ National Institute of General Medical Sciences Grant R01GM118933 (to E.M.L. and R.S.).

${ }^{*}$ S.M.L.B. and A.T.M. contributed equally to this work.

S. M. L. Banks's present address: Department of Biology, Florida Southern College, Lakeland, FL 33801.

A. T. Medeiros's present address: Neuroscience Graduate Program, Brown University, Providence, RI 02912.

M. McQuillan's present address: Neuroscience Graduate Program; Brown University; Providence, RI 02912.

Acknowledgements: We thank Abdullah Rashed Ahmed, Emily Brady, Paul Oliphint, and Rylie Walsh for technical support; Dr. Julia George for the gift of $\alpha$-synuclein constructs and early discussions; and Louie Kerr and Kasia Hammar from the MBL Central Microscopy Facility for providing excellent technical support.

Correspondence should be addressed to Jennifer R. Morgan at jmorgan@mbl.edu.

https://doi.org/10.1523/ENEURO.0448-19.2020

Copyright (C) 2020 Banks et al.

This is an open-access article distributed under the terms of the Creative Commons Attribution 4.0 International license, which permits unrestricted use, distribution and reproduction in any medium provided that the original work is properly attributed. models of PD induces the formation of small oligomers, microaggregates, and filaments at synapses, following a similar pathologic cascade that occurs in other neuronal compartments (Scott et al., 2010; Volpicelli-Daley et al., 2011; Spinelli et al., 2014). This leads to a loss of several critical presynaptic proteins within boutons, which has also been observed in brains of DLB patients (Scott et al., 2010). Perhaps as a consequence, synaptic aggregation of $\alpha$-synuclein is highly correlated with cognitive deficits in some DLB and PD patients (Kramer and Schulz-Schaeffer, 2007; Schulz-Schaeffer, 2010; Ingelsson, 2016). Despite these indications that excess and/or aggregated $\alpha$-synuclein negatively impacts presynaptic functions, the underlying mechanisms are unknown.

Lamprey giant reticulospinal (RS) synapses provide an excellent model for assessing how excess $\alpha$-synuclein affects vertebrate synapses. RS synapses are ideal for these studies because they are amenable to acute perturbations of presynaptic processes (Brodin and Shupliakov, 2006; Walsh et al., 2018), thus permitting a direct evaluation of the effects of excess $\alpha$-synuclein without inducing molecular compensation that occurs after overexpression (Nemani et al., 2010; Scott et al., 2010). Furthermore, the large size of vesicle clusters at RS synapses facilitates detailed ultrastructural analyses of synaptic vesicle trafficking events, allowing us to determine the underlying mechanisms (Morgan et al., 2004, 2013; Busch et al., 2014). We previously reported that acute introduction of excess human $\alpha$-synuclein inhibited synaptic vesicle recycling at lamprey synapses, and the results were consistent with effects on both clathrin-mediated endocytosis (CME) and possibly compensatory bulk endocytosis (Busch et al., 2014; Medeiros et al., 2017, 2018). Similarly, excess $\alpha$-synuclein also inhibited vesicle endocytosis at mammalian calyx of Held synapses (Xu et al., 2016; Eguchi et al., 2017).

We report here a mechanism by which excess $\alpha$-synuclein induces synaptic vesicle recycling defects and present a novel strategy for ameliorating these defects. When introduced acutely, $\alpha$-synuclein selectively impaired CCV uncoating during synaptic vesicle recycling, leading to a depletion of the synaptic vesicle cluster (Medeiros et al., 2017). We further show that human $\alpha$-synuclein, lamprey $\gamma$-synuclein, and several PD-linked mutants directly associate in vitro with $\mathrm{Hsc70}$, the chaperone protein that uncoats CCVs at synapses, thus identifying an interaction that may affect synapses in vivo. Indeed, excess $\alpha$-synuclein reduced $\mathrm{Hsc70}$ availability at stimulated synapses, suggesting Hsc70 sequestration as a possible mechanism underlying the synaptic defects. Consequently, co-injection of exogenous Hsc70 and $\alpha$-synuclein ameliorated the synaptic vesicle trafficking defects. Thus, Hsc70 is an in vivo target of excess $\alpha$-synuclein at synapses, and increasing Hsc70 function reverses the deleterious impacts.

\section{Materials and Methods}

\section{Recombinant proteins}

Cloning of recombinant GST-tagged human $\alpha$-synuclein and His-tagged bovine Hsc70 used for biochemistry 
experiments was as described previously (Wilbanks et al., 1995; Busch and Morgan, 2012; Busch et al., 2014; Sousa et al., 2016). Recombinant proteins were expressed in BL21-CodonPlus (DE3)-RILP Competent Cells (Agilent Technologies) and purified using Glutathione Sepharose 4B Media (GE Healthcare) or Ni-NTA resin (Thermo Fisher Scientific). Untagged human $\alpha$-synuclein used in the microinjection experiments was obtained from rPeptide.

\section{Acute perturbations and electron microscopy}

All animal procedures were approved by the Institutional Animal Care and Use Committee at the MBL in accordance with standards set by the National Institutes of Health. Lampreys (Petromyzon marinus; $11-13 \mathrm{~cm}$; five to seven years old of either sex) were anesthetized in 0.1 g/l MS-222 (Western Chemical Inc.). Spinal cord pieces $(2-3 \mathrm{~cm})$ were dissected and pinned ventral side up in a Sylgard-lined dish. Axonal microinjections were performed as described in Walsh et al., (2018). First, human $\alpha$-synuclein was diluted in lamprey internal solution (180 $\mathrm{mM} \mathrm{KCl}$ and $10 \mathrm{mM}$ HEPES $\mathrm{K}^{+}$; $\mathrm{pH}$ 7.4) to a pipet concentration of $130-160 \mu \mathrm{M}$. In some experiments, recombinant bovine Hsc70 $(27 \mu \mathrm{M})$ was included in the injection pipet either alone or together with $\alpha$-synuclein. Proteins were then loaded into glass microelectrodes (20-25 M $\Omega$ ) and microinjected into giant RS axons using small pulses of $\mathrm{N}_{2}(5-20 \mathrm{~ms}, 30-50 \mathrm{psi}, 0.2 \mathrm{~Hz})$ delivered through a picospritzer. Fluorescein $(10 \mathrm{kDa})$ or tetramethylrhodamine (70 kDa) dextrans (100 $\mu \mathrm{M}$; Thermo Fisher), approximating the molecular weights of $\alpha$-synuclein and Hsc70, respectively, were included in the pipets and coinjected to visualize the proteins' diffusion rates in the axons. Axonal injections resulted in a 10-20x dilution of the proteins. Thus, the final axonal concentration of exogenous human $\alpha$-synuclein was estimated to be $\sim 7-13$ $\mu \mathrm{M}$, and the final concentration of exogenous bovine Hsc70 was $\sim 1-3 \mu \mathrm{M}$. Axons were subsequently stimulated with action potentials $(20 \mathrm{~Hz}, 5 \mathrm{~min})$ using current injections (30-60 nA; $1 \mathrm{~ms}$ ) to induce synaptic vesicle exocytosis/endocytosis.

Spinal cords were fixed immediately after stimulation (3\% glutaraldehyde, $2 \%$ paraformaldehyde in $0.1 \mathrm{M} \mathrm{Na}$ cacodylate; $\mathrm{pH} 7.4$ ), processed for EM, sectioned at 70 $\mathrm{nm}$, and counterstained with uranyl acetate and lead citrate, as described previously (Morgan et al., 2013; Busch et al., 2014; Walsh et al., 2018). Images were obtained at $37,000 \times$ or $59,000 \times$ magnification using a JEOL JEM 200CX electron microscope. We collected EM data on $n$ $=22-33$ synapses from at least two axons from two lampreys per condition and confirmed that the phenotypes reported were consistent between axons/animals. Images were collected at distances surrounding the injection site $(20-150 \mu \mathrm{m})$ where the protein concentration was measurable based on the diffusion of the co-injected fluorescent dye (i.e., the experimental condition), as well as distances farther from the injection site $(150-700 \mu \mathrm{m})$ where no protein had diffused (i.e., the controls). Thus, each EM experiment was internally controlled, as shown in Figure $1 B$, which is necessary due to the variability in the sizes of synaptic vesicle clusters between axons and animals. 3D reconstructions were generated from five serial electron micrographs using Reconstruct software (Fiala, 2005), as described previously (Busch et al., 2014; Medeiros et al., 2017). One image per synapse, taken at or near the center of the active zone, was selected for morphometric analysis. A researcher blinded to the experimental conditions performed the morphometric analyses on all synaptic membranes within a $1-\mu \mathrm{m}$ radius of the active zone using FIJI 2.0.0 (Morgan et al., 2004, 2013; Busch et al., 2014). These included synaptic vesicles, plasma membrane, cisternae, and Clathrin-coated pits (CCPs) and clathrin-coated vesicles (CCVs). Synaptic vesicles were defined as small, clear round vesicles $<100$ $\mathrm{nm}$ in diameter, while "cisternae" were defined as larger vesicles that were $>100 \mathrm{~nm}$ in diameter, as in our previous studies (Busch et al., 2014; Medeiros et al., 2017). Plasma membrane evaginations were determined by drawing a straight line from the edge of the active zone to the nearest position on the axolemma, on both sides of the synapse, and then measuring the curved distance between these points; the mean value per synapse was recorded. CCPs and CCVs were staged as described previously (Morgan et al., 2004). In addition, the SV distribution was determined using a script written in Python (https://github.com/audreytmedeiros/Morgan-Lab),

which measured the distance from the center of each SV to the nearest point on the active zone. After obtaining measurements for each organelle, a total membrane analysis was performed on each synapse to determine how synaptic membranes were redistributed with each perturbation. Here, SV and CCP/V membrane areas were calculated by multiplying the surface area of a sphere $\left(4 \pi r^{2}\right)$ by the number of each type of vesicle at each synapse. Plasma membrane and cisternae areas were obtained by multiplying the length of membrane evaginations and summed cisternae perimeters, respectively, by the section thickness $(70 \mathrm{~nm})$. Graphing and statistical analyses, including Student's $t$ tests and ANOVA, were performed in Origin 7.0 (OriginLab Corp). Data were reported as the mean value per section per synapse.

\section{GST pull downs}

Protein lysates from rat brains or lamprey central nervous system (CNS) (brains and spinal cords) were prepared in HKET buffer ( $25 \mathrm{mM} \mathrm{HEPES} \mathrm{K}{ }^{+}, 150 \mathrm{mM} \mathrm{KCl,} 1$ mM EDTA, and 1\% Triton X-100; $\mathrm{pH}$ 7.4) containing protease inhibitors. GST pull downs were performed using $50-100 \mu \mathrm{g}$ of GST-tagged proteins and either $1-5 \mathrm{mg}$ of rat brain or lamprey CNS extracts or $100 \mu \mathrm{g}$ of purified recombinant proteins. After performing the pull downs, the bound proteins were run on 10\% SDS-PAGE gels and transferred to nitrocellulose membranes. For Western blotting, antibodies were diluted in TBST ( $20 \mathrm{mM}$ Tris $\mathrm{pH}$ 7.6, $150 \mathrm{mM} \mathrm{NaCl}$, and $0.1 \%$ Tween 20 ) with $1 \%$ dry milk or $5 \%$ BSA. Primary antibodies were used at 1:1000 and included: mouse monoclonal anti- $\beta 1 / \beta 2$-adaptins (clone 100/1; Sigma), mouse monoclonal anti-clathrin heavy chain (clone 23; BD Biosciences), mouse monoclonal anti-dynamin (clone 41; BD Biosciences), mouse monoclonal anti-synaptojanin-1 (clone 26; BD Biosciences), 
mouse monoclonal anti-auxilin (gift from Ernst Ungewickell; Ungewickell et al., 1995), rabbit polyclonal anti-Hsc70 (ARP48445; Aviva Systems Biology), and rabbit polyclonal anti-Hsc70 (SPA-816; Enzo Life Sciences). Secondary antibodies were used at 1:1000-1:4000 and included HRP-conjugated goat anti-rabbit, anti-mouse, and antirat IgGs (H + L; Thermo Scientific). The Hsc70 antibodies were validated in lamprey by the appearance of a single protein band of the correct molecular weight matching that in rat brain and by the elimination of that band in secondary only control experiments. Protein bands were detected using Pierce ECL Western blotting substrate (Thermo Scientific). Band intensities were measured using FIJI 2.0.0 software and statistically analyzed in Prism 8.0 (GraphPad Software, Inc.). Data shown in biochemistry figures indicate mean \pm SEM from $n=3-5$ experiments.

\section{Clathrin uncoating assays}

Clathrin cages were assembled with $1 \mu \mathrm{M}$ recombinant bovine brain clathrin and $0.1 \mu \mathrm{M}$ auxilin, as described in Sousa et al. (2016). CCVs were freshly purified from bovine brains as described previously (Keen et al., 1979; Nandi et al., 1982). To visualize the clathrin cages and CCVs, freshly glow-discharged copper grids (EM Sciences) were floated onto a drop of each sample for $5 \mathrm{~min}$, followed by six washes in distilled $\mathrm{H}_{2} \mathrm{O}$, counterstaining in $1 \%$ uranyl acetate for 3 min in the dark. After drying, the grids were imaged on a JEOL JEM 200CX electron microscope at $100 \mathrm{kV}$ using 100,000 $\times$ magnification. Clathrin disassembly from clathrin cages and purified CCVs was measure in vitro by light-scattering experiments conducted in an Applied Photosystems stopped-flow fluorometer with excitation/emission wavelengths of $395 \mathrm{~nm}$ as described in Sousa et al. (2016). Briefly, clathrin cages or purified CCVs corresponding to $0.3 \mu \mathrm{M}$ clathrin heavy chain with $1 \mathrm{mM}$ ATP and $0.45 \mu \mathrm{M}$ auxilin in $20 \mathrm{mM}$ imidazole, $\mathrm{pH}$ 6.8, $10 \mathrm{mM}\left(\mathrm{NH}_{4}\right)_{2} \mathrm{SO}_{4}, 25 \mathrm{mM} \mathrm{KCl}$, and 2 $\mathrm{mM} \mathrm{MgAc} c_{2}$ were reacted with an equal volume of $4 \mu \mathrm{M}$ Hsc70 in the same buffer. Background scattering determined from reactions without cages or CCVs was subtracted from measured scattering values, which were normalized by dividing by the starting scattering value so that the initial scattering in all reactions was 1.0. In some reactions $20 \mu \mathrm{M}$ recombinant human $\alpha$-synuclein (rPeptide) was added to the Hsc70 syringe. Various components were also omitted when indicated as controls. Data were plotted using Origin 7.0 software.

\section{Immunofluorescence (IF) at lamprey synapses}

Recombinant human $\alpha$-synuclein was microinjected into giant RS axons as described above for the EM experiments, after which spinal cords were stimulated using high $\mathrm{K}^{+}(50 \mathrm{mM})$ Ringer for 10 min (Wickelgren et al., 1985). In some experiments, spinal cords were stimulated using action potentials ( $20 \mathrm{~Hz}, 5 \mathrm{~min})$. Following stimulation, spinal cords were fixed in $4 \%$ paraformaldehyde in $0.1 \mathrm{M}$ PBS, pH 7.4, for $3 \mathrm{~h}$, washed in $0.1 \mathrm{M}$ PBS, and incubated for $1 \mathrm{~h}$ in blocking buffer (10\% normal goat serum; Thermo Fisher Scientific) containing 0.3\% Triton $\mathrm{X}-100$. Primary antibody incubations were overnight at $4^{\circ} \mathrm{C}$, followed by $5 \times 1 \mathrm{~h}$ washes in wash buffer $(20 \mathrm{mM}$
$\mathrm{Na}$ phosphate buffer, $450 \mathrm{mM} \mathrm{NaCl}$, and $0.3 \%$ Triton $\mathrm{X}-100 ; \mathrm{pH}$ 7.4). Primary antibodies included: mouse monoclonal anti-SV2 antibody, which was deposited to DSHB by K. M. Buckley (1:100; DSHB; Buckley and Kelly, 1985), rabbit polyclonal anti-Hsc70 (ARP48445; Aviva Systems Biology, Corp.), and rat monoclonal anti-Hsc70 (SPA-815; Enzo Life Sciences). Secondary antibodies used were Alexa Fluor 594 goat anti-mouse $\operatorname{lgG}(\mathrm{H}+\mathrm{L}$; 1:200), Alexa Fluor 488 goat anti-rabbit IgG $(H+L$; ThermoFisher), or DyLight 488 goat anti-rat IgG $(H+L ; 1: 100$; Thermo Fisher). After immunostaining, synapses were imaged within intact whole mounted spinal cords using a Zeiss LSM510 Meta confocal on an Axioskop 2FS microscope. Images were acquired using a Zeiss $40 \times, 0.8 \mathrm{NA}$ Achroplan objective with $3 \times$ optical zoom. All analyses on synapses were performed in FIJI 2.0.0 as follows. Giant RS synapses were first identified using the SV2 labeling, and then the associated Hsc70 puncta ( $\geq 2 \times$ background intensity) that were located on and around the synapses were identified. Those that were overlapping or touching the SV2 puncta were considered to be associated with the synaptic vesicle cluster while those within a $1-\mu \mathrm{m}$ radius of the synapses were located within the endocytic periactive zone. The percentage of synapses containing Hsc70 puncta within each axon, as well as the average number of Hsc70 puncta per synapse, was calculated. All graphing and statistical analyses were performed in GraphPad Prism 8.0 software, including outlier and normality tests (Shapiro-Wilk; D'Agostino and Pearson), as well as statistical comparisons using Student's $t$ test or ANOVA.

\section{Results}

\section{Excess $\alpha$-synuclein impairs clathrin uncoating in vivo during synaptic vesicle recycling}

We previously reported that acute introduction of excess human $\alpha$-synuclein to lamprey RS synapses caused a reduction in the number of synaptic vesicles, which was compensated by an increase in the size of plasma membrane evaginations, as well as greater numbers of irregular membranous cisternae and clathrin-coated structures [i.e., the total number of CCPs and CCVs combined; Busch et al., 2014]. Many of the cisternae originated from the plasma membrane and had CCPs budding from them, suggesting that they were plasma membrane extensions and/or bulk endosomes derived through compensatory endocytosis, though we cannot rule out an effect on recycling endosomes (Chanaday et al., 2019). The phenotype reported is consistent with an impairment of synaptic vesicle recycling via inhibition of CME and possibly bulk endocytosis. Because CME is a predominant mechanism for locally recycling synaptic vesicles at many synapses (Heuser and Reese, 1973; Granseth et al., 2006; Heerssen et al., 2008; Walsh et al., 2018), and because clathrin-mediated vesicle budding is also critical for other modes of SV recycling such as ultrafast and bulk endocytosis (Watanabe et al., 2014; Gan and Watanabe, 2018; Chanaday et al., 2019), we set out to determine in this study exactly how excess $\alpha$-synuclein impacts clathrin- 
mediated processes at synapses and to identify the underlying mechanisms.

To identify how excess $\alpha$-synuclein impairs CME, we first needed to determine which stage or stages were preferentially affected. Briefly, clathrin-mediated vesicle recycling is initiated when clathrin adaptors, AP180 and AP2, recruit clathrin triskelia to the plasma membrane, promoting their assembly into coats (Fig. 1A; Morgan et al., 1999; Saheki and De Camilli, 2012). After maturation of the CCP, vesicle fission occurs through the actions of dynamin, a large GTPase that is abundant at synapses (Takei et al., 1995; Antonny et al., 2016). Synaptojanin is recruited to the neck of the CCP to assist during fission and subsequently in CCV uncoating (Cremona et al., 1999; Chang-lleto et al., 2011). After vesicle fission is complete, the free CCVs are uncoated by the actions of the chaperone protein $\mathrm{Hsc70}$ and its co-chaperone, auxilin (Ungewickell et al., 1995; Morgan et al., 2001). Uncoated vesicles are then refilled with neurotransmitter molecules (Farsi et al., 2018) and returned to the vesicle cluster for subsequent bouts of exocytosis.

As in our prior studies, we microinjected recombinant monomeric human $\alpha$-synuclein into lamprey giant axons, thereby delivering the protein directly to presynapses (Fig. $1 B)$. The axons were subsequently stimulated $(20 \mathrm{~Hz}, 5$ min), fixed, and processed for standard transmission electron microscopy (Walsh et al., 2018). After injection, the final axonal concentration of $\alpha$-synuclein was estimated to be $\sim 7-13 \mu \mathrm{M}$, which is approximately two to four times greater than measurements of endogenous $\alpha$-synuclein at synapses and commensurate with overexpression levels in mammalian PD models and human patients (Singleton et al., 2003; Miller et al., 2004; Nemani et al., 2010; Scott et al., 2010; Westphal and Chandra, 2013). Images of untreated control synapses were collected from the same axon but from regions beyond where the $\alpha$-synuclein protein had diffused (Fig. 1B), thus providing an internal control for each experiment, which is important because of the natural variability in the sizes of synaptic vesicle clusters between axons and animals. At control synapses, local synaptic vesicle recycling was efficient enough to maintain a large synaptic vesicle cluster, and very few CCP/Vs were observed (Fig. $2 A, D$ ). In contrast, after injection of $\alpha$-synuclein, synapses were dramatically altered due to deficits in synaptic vesicle recycling. Specifically, synapses treated with $\alpha$-synuclein exhibited fewer synaptic vesicles, expanded plasma membrane evaginations, increased numbers of large atypical cisternae, and abundant clathrin-coated structures (Fig. 2B,E), as previously reported (Busch et al., 2014; Medeiros et al., 2017). Cisternae were classified as any irregular-shaped vesicles with a diameter $>100 \mathrm{~nm}$ (Busch et al., 2014; Medeiros et al., 2017). These cisternae often had CCPs budding from them and could sometimes be traced back to the plasma membrane (Busch et al., 2014). Strikingly, when we further examined the clathrin-coated structures, we observed atypical clusters of free CCVs at synapses treated with excess $\alpha$-synuclein, a phenotype typically associated with defective CCV uncoating (Fig. 2C, arrows; Cremona et al., 1999; Morgan
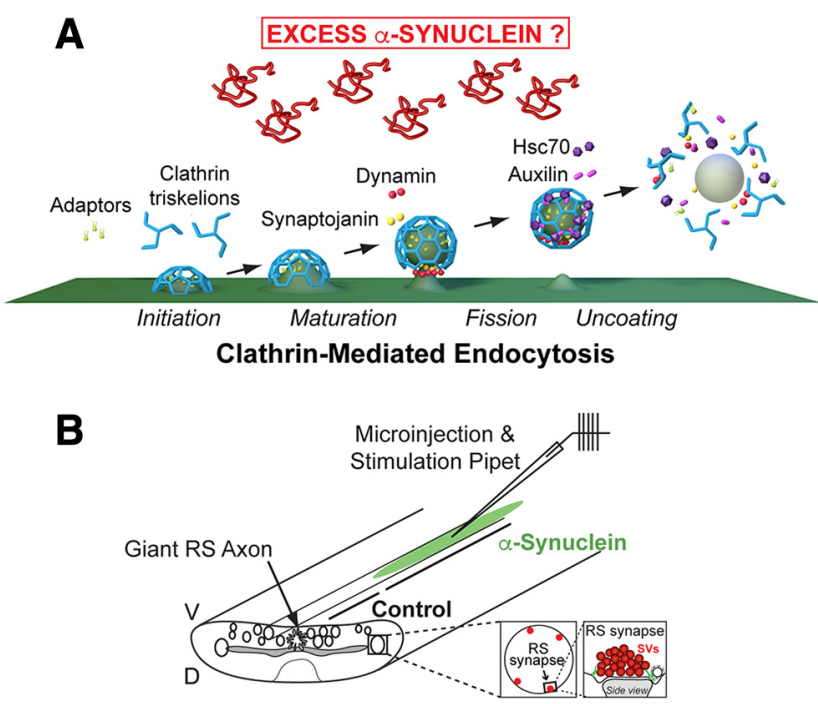

Figure 1. Project goal and lamprey model. $\boldsymbol{A}$, Diagram showing the major stages of clathrin-mediated synaptic vesicle endocytosis and several molecular players. The goal of the study is to determine how excess $\alpha$-synuclein affects this process and the underlying molecular mechanisms. Graphics generated by Jack Cook and Tim Silva (Woods Hole Oceanographic Institution) using Cinema 4D. B, Diagram of the lamprey spinal cord showing microinjection strategy and location of RS synapses. All electron microscopy experiments were internally controlled such that the control synapses were taken from a region of the injected axon beyond which the reagents (e.g., $\alpha$-synuclein) had diffused. $\mathrm{D}=$ dorsal; $\mathrm{V}=$ ventral.

et al., 2001). 3D reconstructions generated from serial micrographs revealed the gross alterations in synaptic structure caused by $\alpha$-synuclein (Fig. 2D,E). Whereas control synapses exhibited only a few CCPs and CCVs close to the plasma membrane, the $\alpha$-synuclein treated synapses exhibited dozens of free CCVs that were dispersed throughout the synaptic area (Fig. 2D,E, insets).

We performed a quantitative morphometric analysis of all synaptic membranes within $1 \mu \mathrm{m}$ of the active zone and confirmed that excess $\alpha$-synuclein impaired synaptic vesicle recycling, as demonstrated by a loss of synaptic vesicles (Fig. $2 F$ ) that was compensated by larger plasma membrane evaginations (Fig. 2/; synaptic vesicles, control: $150 \pm 11 \mathrm{SVs} /$ section, $n=31$ synapses, $n=2$ axons; $\alpha$-Synuclein: $98 \pm 12$ SVs; $n=30$ synapses, $n=2$ axons; Student's $t$ test; $p<0.005$; plasma membrane, control: $1.75 \pm 0.07 \mu \mathrm{m}, n=32$ synapses, $n=2$ axons; $\alpha$-Synuclein: $2.37 \pm 0.12 \mu \mathrm{m} ; n=30$ synapses, $n=2$ axons; Student's $t$ test; $p<0.00005)$. The remaining synaptic vesicles were of normal size (diameter; control: $54.7 \pm 0.6$ $\mathrm{nm}, n=200 \mathrm{SVs}, n=10$ synapses; $\alpha$-Synuclein: $52.9 \pm$ $0.9 \mathrm{~nm} ; n=200$ SVs, $n=10$ synapses; Student's $t$ test; $p=0.10)$. However, the SVs were slightly more dispersed (Fig. 2G) and redistributed to longer distances from the active zone after treatment with $\alpha$-synuclein (Fig. $2 \mathrm{H}$; $<500 \mathrm{~nm}$, control: $78.87 \pm 2.81 \%$; $\alpha$-Synuclein: $66.72 \pm$ $3.71 \%$; $>500 \mathrm{~nm}$, control: $20.81 \pm 2.80 \%$; $\alpha$-Synuclein: $33.28 \pm 3.71 \% ; n=30-32$ synapses, $n=2$ axons; ANOVA $p<0.0001$; Tukey's post hoc $p<0.05$ ), which is consistent with the phenotype reported in hippocampal 

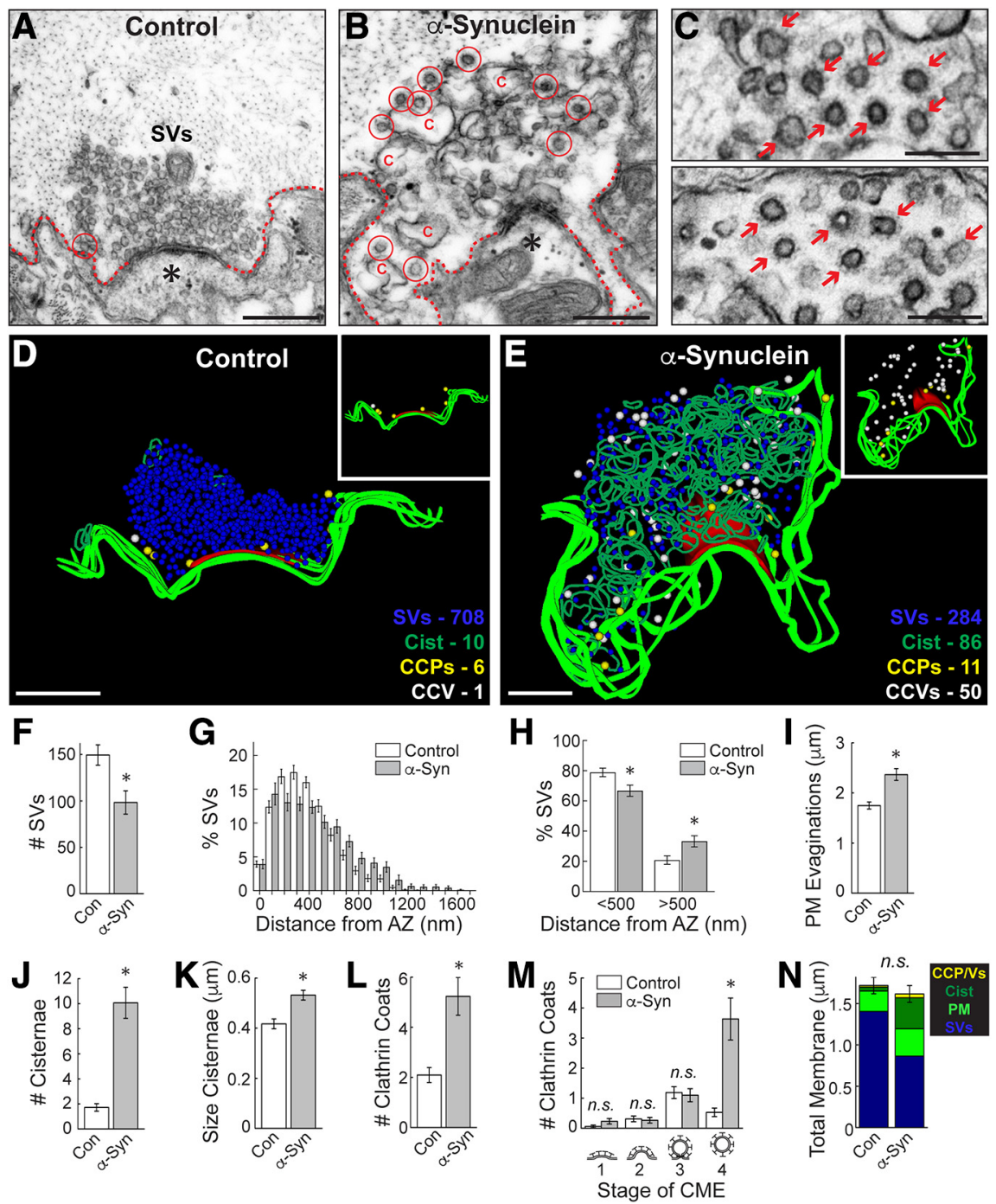

Figure 2. Excess $\alpha$-synuclein impairs CCV uncoating during synaptic vesicle recycling. $\boldsymbol{A}, \boldsymbol{B}$, Electron micrographs of untreated, control lamprey synapses stimulated at $20 \mathrm{~Hz}$ for $5 \mathrm{~min}$. After stimulation, control synapses have large synaptic vesicle (SV) clusters, shallow plasma membrane (PM) evaginations (dotted lines), and only a few CCP/Vs (circles). In contrast, synapses treated with excess human $\alpha$-synuclein had smaller SV clusters, larger PM evaginations, and greater numbers of CCP/Vs, indicative of a vesicle recycling defect. Asterisks mark postsynaptic spines. Scale bars $=500 \mathrm{~nm}$. C, Insets show clusters of free CCVs at synapses after treatment with $\alpha$-synuclein (arrows). Scale bars $=200 \mathrm{~nm}$. $\boldsymbol{D}, \boldsymbol{E}, 3 \mathrm{D}$ reconstructions comparing control and $\alpha$-synuclein treated synapses. $\alpha$-Synuclein caused severe endocytic defects, including a striking increase in CCVs (white spheres) and cisternae (dark green traces). Insets show the distributions of CCPs (yellow spheres) and CCVs (white spheres). While CCP/Vs at control synapses are sparse and localized near the plasma membrane at control synapses ( $\boldsymbol{D}$, inset), $\alpha$-synuclein treated synapses exhibited large numbers of free CCVs throughout the synaptic area with little change in CCPs (E, inset). Active zone is shown in red. Scale bars $=500 \mathrm{~nm}$. $\boldsymbol{F}-\boldsymbol{N}$, The SV recycling defect induced by $\alpha$-synuclein is demonstrated by a loss of SVs $(\boldsymbol{F})$ and synaptic vesicle dispersion $(\boldsymbol{G}, \boldsymbol{H})$, which was compensated by larger PM evaginations $(\boldsymbol{I})$ and greater numbers/size of cisternae $(\boldsymbol{J}, \boldsymbol{K})$ as well as CCP/Vs $(\boldsymbol{L})$. The selective increase in CCVs (stage 4) indicates a clathrin uncoating defect $(\boldsymbol{M})$. Total membrane analysis reveals a redistribution of synaptic membranes reflecting the endocytic defect. Bars represent mean \pm SEM (per section, per synapse) from $n=30-33$ synapses, $n=2$ axons, $n=2$ animals/condition. Asterisks denote significance $(p<0.05)$ by Student's $t$ test $(\boldsymbol{F}, \boldsymbol{I}-\boldsymbol{L}, \boldsymbol{N})$ or ANOVA $(\boldsymbol{H}, \boldsymbol{M})$. n.s. $=$ not significant by ANOVA.

synapses from transgenic mice overexpressing human $\alpha$-synuclein (Nemani et al., 2010). Corroborating the vesicle recycling defect, the number and the size (perimeter) of the cisternae were also significantly increased (Fig. 2J,K; \#cisternae, control: $1.7 \pm 0.3$ cisternae, $n=32$ synapses, $n=2$ axons; $\alpha$-Synuclein: $10.1 \pm 1.2$ cisternae; $n=30$ synapses, $n=2$ axons; Student's $t$ test; $p<$ 0.00001; size cisternae, control: $0.42 \pm 0.02 \mu \mathrm{m}, n=55$ cisternae, $n=32$ synapses; $\alpha$-Synuclein: $0.53 \pm 0.02 \mu \mathrm{m}$; $n=302$ cisternae, $n=30$ synapses; Student's $t$ test; $p<$ 0.05). Supporting effects on CME, the total numbers of clathrin coats (CCPs $+\mathrm{CCVs}$ ) were increased 2- to 3-fold (Fig. 2L; \#clathrin coats, control: $2.1 \pm 0.3$ coats, $n=32$ synapses, $n=2$ axons; $\alpha$-Synuclein: $5.2 \pm 0.8$ coats, $n=$ 30 synapses, $n=2$ axons; Student's $t$ test; $p<0.0005$ ). Further dissection of the stages of CME revealed that 
$\alpha$-synuclein selectively increased the number of free CCVs (stage 4) without significantly altering the earlier stages of CCP formation (stages 1-3; Fig. 2M; stage 1, control: $0.06 \pm 0.04 \mathrm{CCPs} /$ section; $\alpha$-Synuclein: $0.23 \pm$ 0.09 CCPs; stage 2, control: $0.31 \pm 0.09 \mathrm{CCPs}, \alpha-\mathrm{Sy}-$ nuclein: $0.27 \pm 0.10 \mathrm{CCPs}$; stage 3 , control: $1.19 \pm 0.20$ CCPs; $\alpha$-Syn: $1.10 \pm 0.22$ CCPs; stage 4, control: $0.53 \pm$ 0.14 CCVs, $\alpha$-Synuclein: $3.63 \pm 0.70$ CCVs; $n=30-32$ synapses, $n=2$ axons; ANOVA $p<0.0000005$, Tukey's post hoc). A total membrane analysis shows that the loss of synaptic vesicle membrane area was compensated by an expansion of the plasma membrane, cisternae, and CCP/Vs (Fig. $2 N$; control $1.7 \pm 0.1 \mu \mathrm{m}^{2} ; \alpha$-Syn: $1.6 \pm 0.1$ $\mu \mathrm{m}^{2} ; n=30-32$ synapses; Student's $t$ test; $p=0.47$ ). Taken together, these data indicate that excess $\alpha$-synuclein impairs clathrin-mediated synaptic vesicle recycling with selective effects on CCV uncoating (Medeiros et al., 2017, 2018). The larger plasma membrane evaginations and increased cisternae suggest additional effects of $\alpha$-synuclein on initiation of CME (Vargas et al., 2014), although this could also be an indirect consequence of trapping limiting amounts of clathrin and coat proteins within the uncoated CCVs (Morgan et al., 2001).

\section{$\alpha$-Synuclein interacts with Hsc70, the uncoating ATPase at synapses}

To determine how $\alpha$-synuclein impairs clathrin uncoating, we next tested for possible interactions between $\alpha$-synuclein and several key players that mediate CME at synapses, including those involved in the clathrin uncoating process (Fig. $1 A$; Saheki and De Camilli, 2012). Human $\alpha$-synuclein consists of a highly conserved $\mathrm{N}$-terminal domain (NTD; amino acids (a.a.) 1-95), which folds into an amphipathic $\alpha$-helix on interaction with small vesicles and includes the non-A $\beta$ component (NAC) domain (a.a. 6195), followed by a less-structured acidic C-terminal domain (a.a. 96-140; Fig. 3A). GST-tagged human $\alpha$-synuclein was used in pull-down experiments to test for any binding partners isolated from rat brain protein extracts. In the GST pull downs, no interactions were observed between $\alpha$-synuclein and $\beta$-adaptin (an AP2 subunit), clathrin heavy chain, dynamin, synaptojanin, or auxilin (Fig. 3B). In contrast, full-length $\alpha$-synuclein, as well as a truncation containing the highly conserved NTD (a.a. 1-102), selectively pulled down Hsc70, the chaperone protein that uncoats CCVs at synapses [Fig. 3C; beads: $2.1 \pm 2.5$ arbitrary units (AU); GST: $22.3 \pm 10.2$ AU; GST- $\alpha$ Syn: $155.2 \pm 8.0$ AU; GST-NTD: $164.2 \pm 4.1$ AU; $n=3$; ANOVA $p<0.0001$; Tukey's post hoc]. Previous studies also reported an interaction between Hsc70 and $\alpha$-synuclein with two identified binding regions within the first 102 amino acids (Pemberton et al., 2011; Redeker et al., 2012). Demonstrating conservation of the interaction, GST- $\alpha$-synuclein and NTD also pulled down endogenous Hsc70 from lamprey brain and spinal cord extracts (Fig. 3C, bottom; beads: $0.3 \pm 0.6 \mathrm{AU}$; GST: $5.7 \pm 3.1 \mathrm{AU}$; GST- $\alpha$ Syn: $106.4 \pm 17.2 \mathrm{AU}$; GST-NTD: $153.5 \pm 15.3 \mathrm{AU}$; $n=3$; ANOVA $p<0.0001$, Tukey's post hoc). We repeated the pull downs using GST-tagged lamprey $\gamma$-synuclein, which is the most highly expressed synuclein isoform in the lamprey giant RS neurons (Busch and Morgan, 2012). Full-length lamprey $\gamma$-synuclein is $56 \%$ identical and $63 \%$ similar to human $\alpha$-synuclein, and its $\alpha$-helical NTD is $67 \%$ identical and $90 \%$ similar to the corresponding region of human $\alpha$-synuclein (Fig. 3A, bottom; Busch and Morgan, 2012; Busch et al., 2014). Further corroborating this conserved interaction, lamprey $\gamma$-synuclein and its NTD also pulled down Hsc70 from rat brain extracts (Fig. 3D; beads: $1.4 \pm 0.9$ AU; GST: $2.9 \pm$ 1.3 AU; GST- $\gamma$ Syn: $134.9 \pm 34.9$ AU; GST-NTD: $153.3 \pm$ 15.6 AU; $n=3$; ANOVA $p<0.001$; Tukey's post hoc).

To determine whether the $\mathrm{Hsc} 70 / \alpha$-synuclein interaction is direct and to further map it, the GST pull downs were repeated using purified, recombinant bovine $\mathrm{Hsc} 70$. Hsc70 consists of a highly conserved $\mathrm{N}$-terminal nucleotide-binding domain (NBD), and a substratebinding domain (SBD) with a more variable $10 \mathrm{kDa}$ C-terminal region (Fig. 3E). While the affinity of Hsc70 for typical client polypeptides is normally modulated by nucleotides (ATP/ADP), we performed the pull downs without nucleotides because prior studies reported more effective binding and sequestration of $\alpha$-synuclein by Hsc70 in fibrillation assays under nucleotide-free conditions (Pemberton et al., 2011; Redeker et al., 2012). Under these conditions, GST-tagged human $\alpha$-synuclein and its NTD pulled down bovine Hsc70, indicating a direct interaction (Fig. 3F, top; GST: $8.3 \pm 1.6$ AU; GST-Syn: $68.1 \pm$ 5.3 AU; GST-NTD: $67.9 \pm 3.9 \mathrm{AU} ; n=3$; ANOVA $p=5 \times$ $10^{-5}$; Tukey's post hoc). Similarly, lamprey $\gamma$-synuclein and its NTD also pulled down bovine $\mathrm{Hsc70}$ in these direct binding assays (Fig. 3G, top; GST: $1.5 \pm 0.4 \mathrm{AU}$; GSTSyn: $48.9 \pm 11.6 \mathrm{AU}$; GST-NTD: $62.8 \pm 9.6 \mathrm{AU} ; n=3$; ANOVA $p=0.006$; Tukey's post hoc). To further map the interaction, we additionally tested the binding of $\alpha$-synuclein to several Hsc70 truncation mutants. One truncation consisted of only the NBD (a.a. 1-383), and the other contained the NBD and SBD but lacked the C-terminal $10 \mathrm{kDa}$ region (Hsc70 $\Delta$ C; a.a. 1-554; Fig. 3E; Flaherty et al., 1990; Wilbanks et al., 1995). Both truncation mutants are well expressed, folded, stable, soluble, and exhibit ATP and ADP binding affinities and ATP hydrolysis activity like full length Hsc70 (Wilbanks et al., 1995; Zhang and Zuiderweg, 2004; Jiang et al., 2005). Neither human $\alpha$-synuclein, lamprey $\gamma$-synuclein, nor the NTDs pulled down the Hsc70 truncation mutants that were missing the $\mathrm{C}$-terminal fragments, indicating a role for the $\mathrm{C}$ terminus in mediating or stabilizing the interaction (Fig. 3F,G, middle and bottom). Taken together, these data indicate that the $\mathrm{N}$ terminus of $\alpha$-synuclein interacts directly with Hsc70 via an interaction that is conserved between synuclein orthologs and disrupted by the deletion of the $\mathrm{C}$ terminus of $\mathrm{Hsc} 70$.

We repeated the pull downs using the $\alpha$-synuclein point mutants that are linked to PD: A30P, E46K, and A53T (Fig. $4 A$ ). All three mutants bound directly to bovine Hsc70 (Fig. $4 B-D$ ). While A30P and A53T did not exhibit any statistically significant differences in binding efficacy, as compared to wild-type $\alpha$-synuclein, E46K binding to Hsc70 was slightly reduced (Fig. 4B-D; GST: $1.1 \pm 0.3 \mathrm{AU}$; GST-Syn: $75.0 \pm 6.9$ AU; GST-A30P: $57.0 \pm 11.8 \mathrm{AU} ; n=$ 
A

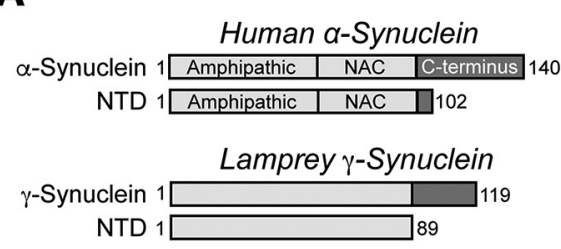

B
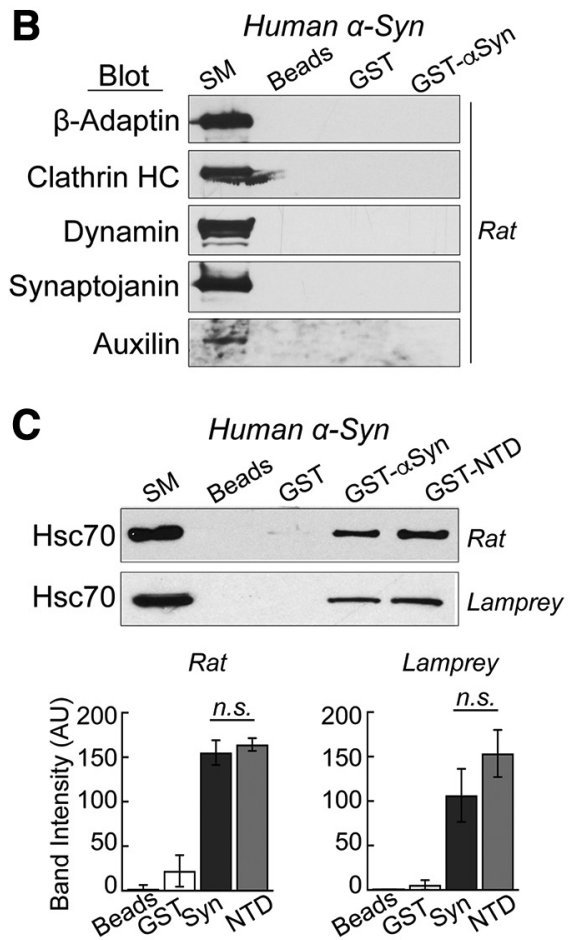
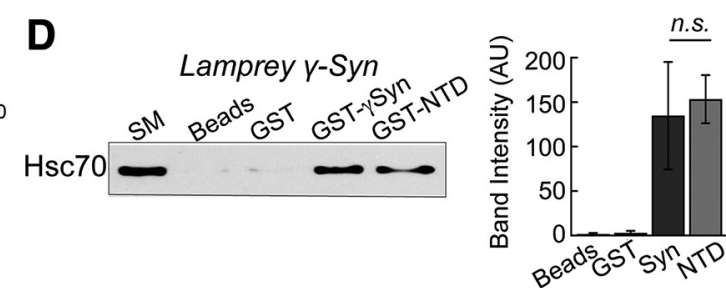

$\mathbf{E}$

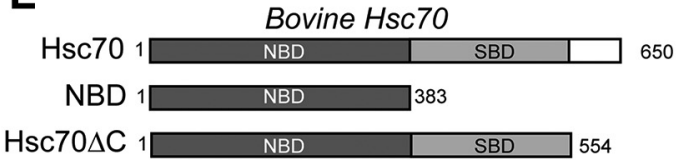

$\mathbf{F}$
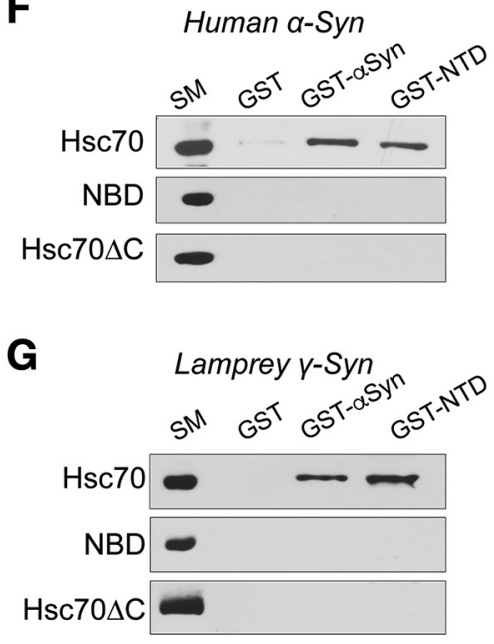
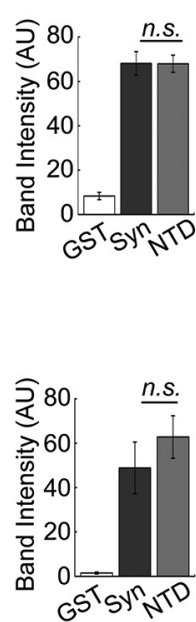

Figure 3. $\alpha$-Synuclein interacts directly with Hsc70, the chaperone protein that uncoats CCVs during synaptic vesicle recycling. $\boldsymbol{A}$, Domain diagrams of full-length human $\alpha$-synuclein, lamprey $\gamma$-synuclein and their respective NTDs. $\boldsymbol{B}$, GST pull downs from rat brain lysates revealed no detectable interactions between $\alpha$-synuclein and several major components of CME including AP2, clathrin, dynamin, synaptojanin, and auxilin. SM = starting material. Blots shown are representative of $n=3$ experiments. $\boldsymbol{C}$, In contrast, human $\alpha$-synuclein and its NTD pulled down Hsc70 from rat brain and lamprey CNS lysates. $\boldsymbol{D}$, Similarly, lamprey $\gamma$-synuclein pulled down Hsc70 from rat brain lysates, demonstrating conservation of the interaction. $\boldsymbol{E}$, Domain diagrams of bovine Hsc70 and several truncations used in the experiments. $\boldsymbol{F}, \mathbf{G}$, In direct binding assays, both human $\alpha$-synuclein and lamprey $\gamma$-synuclein, and their NTDs, pulled down recombinant bovine Hsc70. No interactions were detected with either NBD or Hsc70 $\Delta \mathrm{C}$, indicating a role for the $\mathrm{C}$ terminus. In panels $\boldsymbol{C}, \boldsymbol{D}, \boldsymbol{F}, \boldsymbol{G}$, bars represent mean \pm SEM from $n=3$ independent experiments. n.s. $=$ not significant by ANOVA $(p>0.05)$.

5; ANOVA $p<0.0001$; Tukey's post hoc; GST: $11.5 \pm 2.3$ AU; GST-Syn: $97.8 \pm 5.5 \mathrm{AU}$; GST-E46K: $75.2 \pm 6.3 \mathrm{AU}$; $n=3$; ANOVA $p<0.0001$; Tukey's post hoc; GST: $6.1 \pm$ 4.4 AU; GST-Syn: $68.0 \pm 6.8 \mathrm{AU}$; GST-A53T: $67.1 \pm 3.2$ $\mathrm{AU} ; n=5$; ANOVA $p<0.0001$; Tukey's post hoc).

\section{$\alpha$-Synuclein does not affect Hsc70-mediated clathrin disassembly in vitro}

Taken together, the above results showing the in vivo clathrin uncoating defect and in vitro interaction between Hsc70 and $\alpha$-synuclein suggest that when in excess, $\alpha$-synuclein may interact with Hsc70 and alter its CCV uncoating function at synapses. Among the possible mechanisms, $\alpha$-synuclein could interfere with Hsc70 uncoating activity and/or alter Hsc70 availability at synapses. We began testing these possibilities by examining whether $\alpha$-synuclein affects the ability of Hsc70 to pro- mote clathrin cage disassembly in vitro using a light scattering assay as previously described (Sousa et al., 2016). In one set of experiments, we used empty clathrin cages assembled in vitro (Fig. 5A). In a typical reaction, Hsc70 binds the clathrin cages and subsequently uncoats clathrin, as indicated by a transient increase in light scattering followed by an exponential decrease in scattering intensity as the clathrin is disassembled (Fig. $5 \mathrm{~A}$, blue trace). Even when $\alpha$-synuclein was in excess of $\mathrm{Hsc} 70$, it had no effect on the disassembly of clathrin cages (Fig. $5 A$, red trace).

It is well established that $\alpha$-synuclein interacts in vitro with small vesicles containing anionic lipids and in vivo with synaptic vesicles, and such vesicle interactions promote folding of the NTD into an $\alpha$-helix (Maroteaux et al., 1988; Davidson et al., 1998; Fortin et al., 2005; Burré et al., 2015). Thus, because $\alpha$-synuclein effects on un- 
A
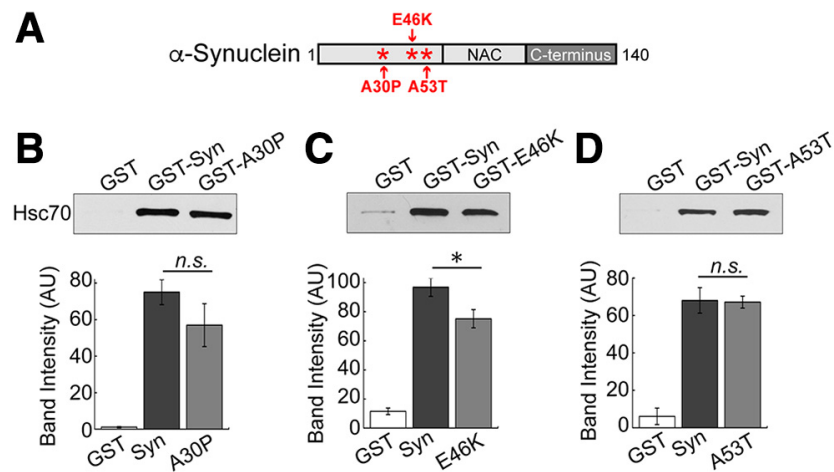

Figure 4. PD-associated $\alpha$-synuclein mutants also interact directly with $\mathrm{Hsc} 70$. $\boldsymbol{A}$, Diagram showing the locations of PD-linked point mutations A30P, E46K, and A53T, which occur within the alpha helical NTD of $\alpha$-synuclein. $\boldsymbol{B}-\boldsymbol{D}$, In direct binding assays, GST-tagged A30P, E46K, and A53T all pulled down Hsc70 to a similar degree as wild-type $\alpha$-synuclein. Only binding to E46K was slightly reduced. Bars represent mean \pm SEM from $n=3-5$ experiments. Asterisk indicates significance $(p=0.04)$; n.s. $=$ not significant by ANOVA.

coating may require membrane binding, we repeated the in vitro clathrin uncoating experiments using CCVs purified from bovine brains, which contained the underlying endocytic vesicle membranes (Fig. $5 B$ ). Under these conditions, some binding of $\alpha$-synuclein to purified CCVs occurred, as indicated by an initial increase in light scattering (Fig. 5B, green trace). As with the clathrin baskets, Hsc70 also bound and disassembled purified CCVs, although the decay in light scattering was less pronounced due to the presence of the vesicular membranes in the reaction (Fig. 5B, blue trace). Excess $\alpha$-synuclein also had no obvious effect on Hsc70-mediated uncoating of purified CCVs (Fig. 5B, red trace). Using these highly optimized, reduced conditions, we thus conclude that $\alpha$-synuclein does not directly interfere with the kinetics or core process of Hsc70-mediated clathrin uncoating in vitro.

\section{Excess $\alpha$-synuclein inhibits Hsc70 availability at synapses}

Compared to the in vitro assays, the complex in vivo environment of synapses permits a more physiologic partitioning of $\alpha$-synuclein and Hsc70 between cytosol and synaptic membranes, raising the possibility of observing more functional interactions. We therefore examined whether excess $\alpha$-synuclein affects the localization of Hsc70 in vivo at lamprey synapses. To do so, we performed whole mount immunostaining in the lamprey spinal cord for Hsc70 and SV2, a marker of synaptic vesicle clusters, and then imaged the Hsc70 in the vicinity of the synapses. Giant RS synapses are large en passant synapses (1-2 $\mu \mathrm{m}$ in diameter; 1000-2000 synaptic vesicles), which reside along the periphery of the giant RS axons (Fig. 1B, inset). They comprise large synaptic vesicle clusters at the active zone, which are surrounded by a distinct actin-rich periactive zone where clathrin-mediated synaptic vesicle recycling occurs (Fig. 6A; Shupliakov et al., 2002; Morgan et al., 2004; Bourne et al., 2006; Saheki and
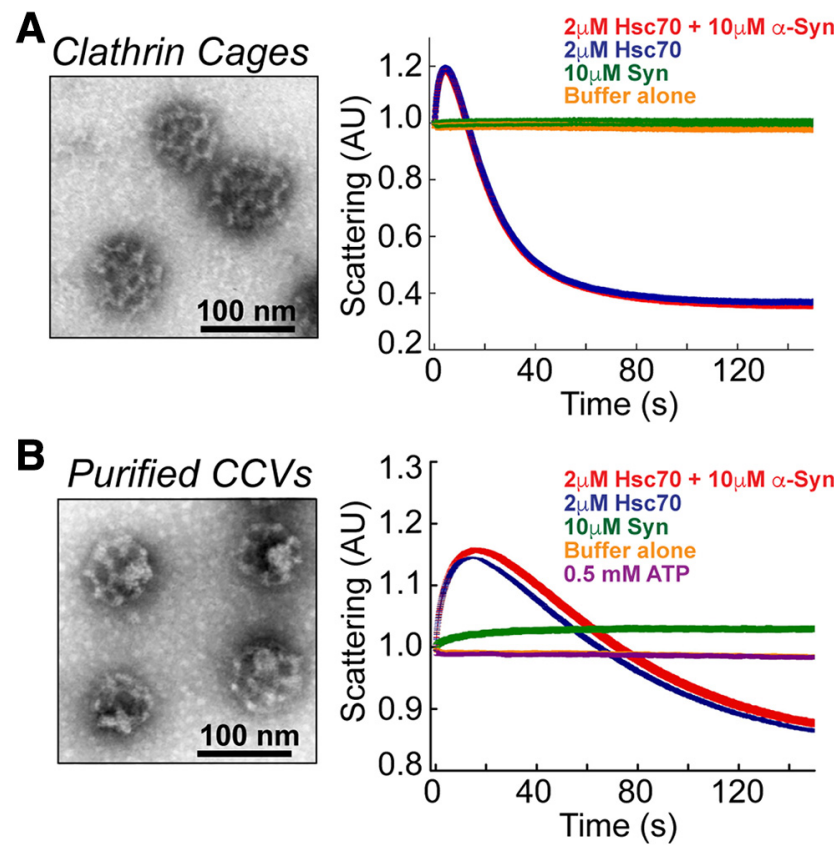

Figure 5. $\alpha$-Synuclein does not affect Hsc70-mediated clathrin disassembly in vitro. $\boldsymbol{A}$, left, Clathrin cages were assembled in vitro using recombinant clathrin heavy chain and auxilin, as described in Sousa et al. (2016). Right, An in vitro light scattering assay showed that addition of $2 \mu \mathrm{M}$ Hsc70 exponentially reduced the light scattering intensity as clathrin cages were disassembled (blue trace). Addition of $10 \mu \mathrm{M} \alpha$-synuclein did not alter the rate of Hsc70-mediated clathrin disassembly (red trace). No change in light scattering was observed in baseline control measurements after addition of buffer (yellow trace) or $10 \mu \mathrm{M}$ $\alpha$-synuclein alone (green trace). $\boldsymbol{B}$, left, CCVs, which contain the underlying endocytic vesicle membranes, were freshly purified from bovine brains. Right, $\alpha$-Synuclein alone slightly increased light scattering (green trace), which is likely due to its binding to the endocytic vesicles. Similar to the results with clathrin cages, introduction of $10 \mu \mathrm{M} \alpha$-synuclein did not significantly affect the dynamics of Hsc70-mediated CCV uncoating (blue vs red trace).

De Camilli, 2012). To detect Hsc70, we used an Hsc70 antibody (Aviva ARP48445 rabbit polyclonal) that detects a single $70 \mathrm{kDa}$ band in both lamprey and rat brain lysates by Western blotting (Fig. 6B). After immunostaining the spinal cords, the giant RS synapses were first identified using a monoclonal SV2 antibody, which labels presynaptic vesicle clusters in all vertebrates tested, including lampreys (Fig. 6C,D; Buckley and Kelly, 1985; Busch et al., 2014). The synapse-associated Hsc70 was subsequently evaluated. The Hsc70 antibody immunolabeled distinct puncta within axons and around RS synapses, as observed at mammalian synapses (Wilhelm et al., 2014), as well as diffuse patches (Fig. $6 C, D$ ). Although Hsc70 is one of the most abundant proteins in neurons, the IF signals at both lamprey and mammalian synapses is dimmer than expected, which may be due to some Hsc70 being tightly bound in chaperone protein complexes and therefore inaccessible for immunolabeling. At unstimulated control synapses, the immunolabeled Hsc70 puncta were fairly sparse and in low abundance (Fig. 6C, top 
A

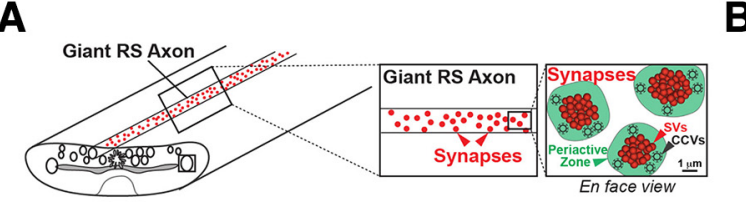

C

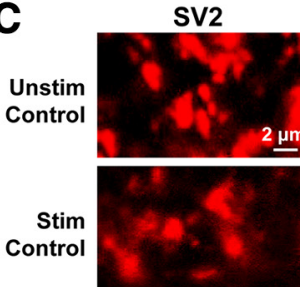

SV2
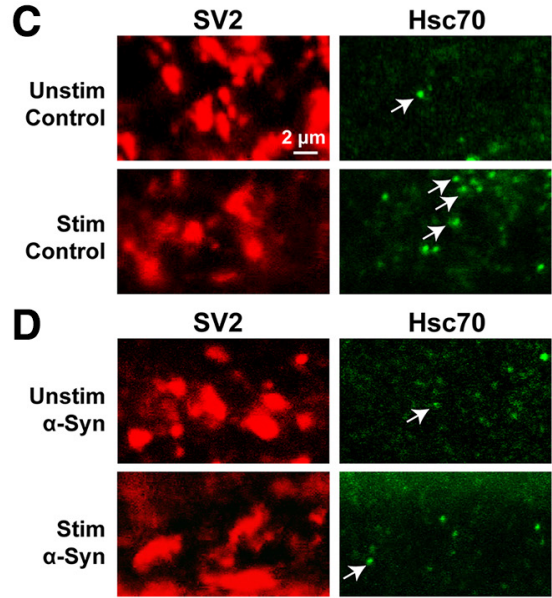

Hsc70
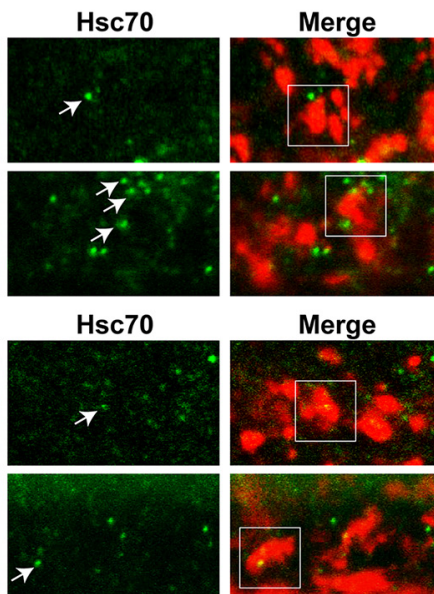

Merge
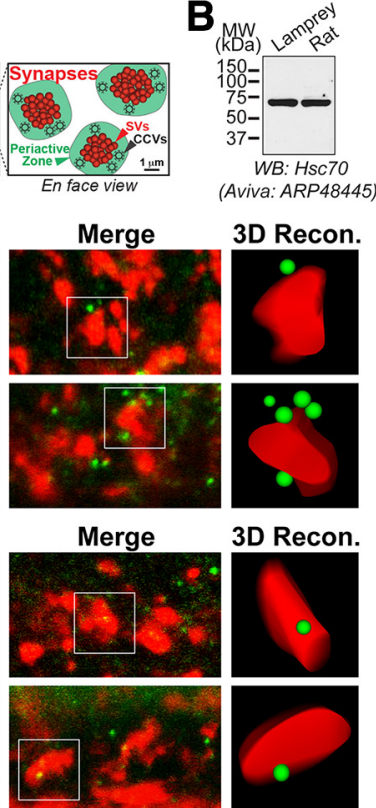

3D Recon

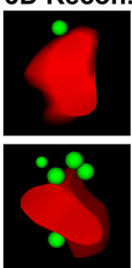

3D Recon.
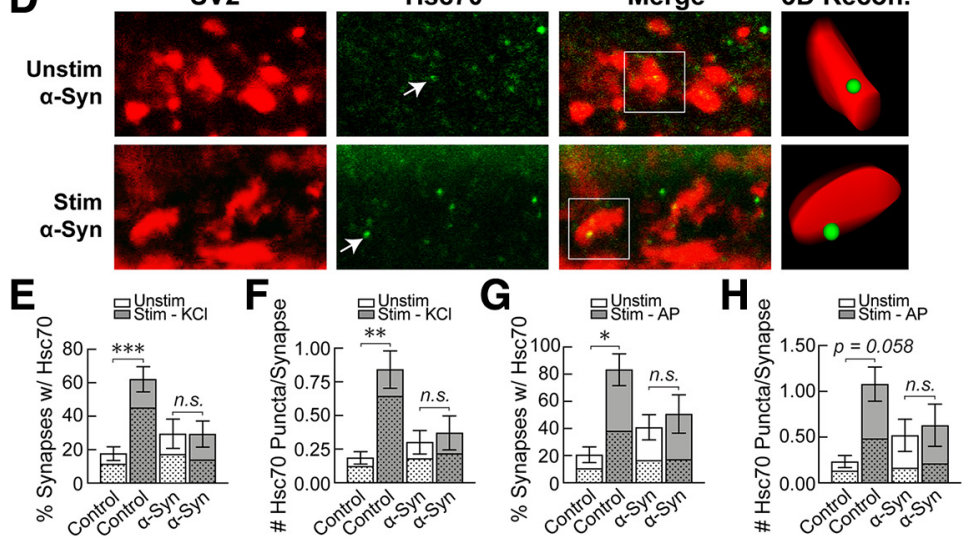

Figure 6. Excess $\alpha$-synuclein inhibits Hsc70 availability at lamprey synapses. A, Diagram showing the basic organization of the giant RS synapses within lamprey spinal cord. The large synaptic vesicle (SV) clusters (red) are surrounded by a distinct periactive zone where CME occurs (green). B, By Western blotting, the Hsc70 antibody used for these experiments (Aviva ARP48445) specifically recognized a single band at $70 \mathrm{kDa}$ in both lamprey CNS and rat brain lysates, consistent with the expected molecular weight of Hsc70. C, Confocal images showing clusters of giant synapses immunostained for the synaptic vesicle-associated protein SV2 (red) and Hsc70 (green). Compared to unstimulated conditions, stimulation with high $\mathrm{K}^{+}$increased Hsc70 availability at synapses, as evidenced by an increase in the number of visible Hsc70 puncta (arrows). $\boldsymbol{D}$, In contrast, $\alpha$-synuclein inhibited the stimulationdependent increase in Hsc70 at synapses. $\boldsymbol{E}, \boldsymbol{F}$, Graphs showing the percentage of synapses (per axon) with associated Hsc70 puncta, as well as the average number of Hsc70 puncta per synapse. Bars represent mean \pm SEM from $n=76-135$ synapses, $n=$ 5-13 axons, $n=5-7$ animals/condition; $* p<0.05, * * p<0.01$, $* * * p<0.001$, $* * * * p<0.0001$; n.s. = not significant by ANOVA. G, $\boldsymbol{H}$, Similar results were obtained using action potential stimulation $(20 \mathrm{~Hz}, 5 \mathrm{~min})$ and a different Hsc70 antibody (Enzo Life Sciences SPA815). Bars represent mean \pm SEM from $n=31-47$ synapses, $n=3-4$ axons, $n=2-3$ animals/condition; $* p<0.05, * * p<0.01$; n.s. = not significant by ANOVA. In panels $\boldsymbol{E}-\boldsymbol{H}$, the stippled regions of the bars represent the proportion of Hsc70 puncta overlapping or touching the SV cluster, while the clear regions indicate the proportion localized within the periactive zone.

row). In contrast, stimulation using high $\mathrm{K}^{+}$induced an increase in Hsc70 puncta within or adjacent to the synaptic vesicle clusters, indicating enhanced Hsc70 availability at synapses (Fig. 6C, second row). The average size of Hsc70 puncta was $0.20 \pm 0.004 \mu \mathrm{m}^{2}(n=174$ puncta, $n=132$ synapses, $n=33$ axons). Next, as with the EM experiments, we injected human $\alpha$-synuclein to a final axonal concentration of 7-13 $\mu \mathrm{M}$ (see Materials and Methods). Measurements of endogenous $\alpha$-synuclein range from 3-6 $\mu \mathrm{M}$ (Westphal and Chandra, 2013) to 45 $\mu \mathrm{M}$ (Wilhelm et al., 2014), suggesting that the total $\alpha$-synuclein concentration after injection in lamprey axons could be anywhere between 10-58 $\mu \mathrm{M}$, which is submolar to equimolar with measurements of endogenous Hsc70 in rat synaptosomes (55 $\mu \mathrm{M}$; Wilhelm et al., 2014). After introducing excess $\alpha$-synuclein, the stimulationdependent increase in $\mathrm{Hsc70}$ at presynapses was no longer observed, suggesting an in vivo interaction with $\alpha$-synuclein (Fig. 6D). Next, we quantified all of the Hsc70 puncta associated with synapses, both those directly touching or overlapping the synaptic vesicle cluster, as well as those within a $1-\mu \mathrm{m}$ radius of the synaptic vesicle cluster, representing the endocytic periactive zone (Fig. $6 A)$. In Figure $6 E-H$, the stippled regions of the bars indicate the proportion of Hsc70 puncta associated with the synaptic vesicle cluster $(30-77 \%$ across all conditions), while the unmarked regions indicate the Hsc70 puncta localized exclusively within the periactive zone. At lamprey synapses, many endocytic proteins involved in CME are localized to synaptic vesicle clusters, as well as the periactive zone (Evergren et al., 2004, 2006), and so both pools of Hsc70 may be involved in synaptic vesicle endocytosis. In unstimulated control axons, $<20 \%$ of synapses per axon had clearly defined immunolabeled Hsc70 puncta associated with them (Fig. 6E). Stimulation induced a significant 3-fold increase in the percentage of 

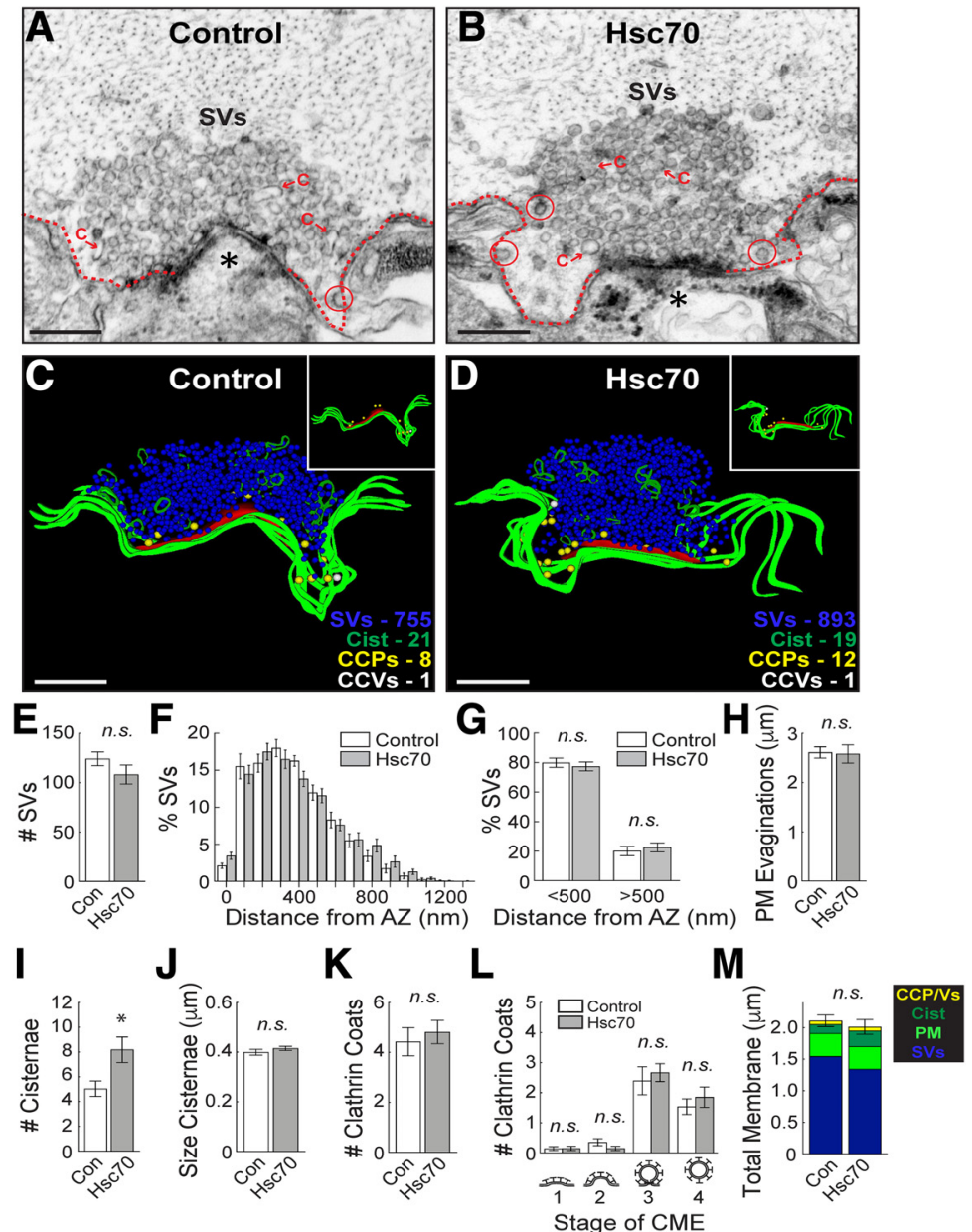

Figure 7. Increasing Hsc70 alone has no effect on CME at synapses. A, B, Hsc70 does not dramatically alter synaptic morphology, as demonstrated by the large synaptic vesicle (SV) clusters, shallow plasma membrane evaginations (dotted lines), and few CCP/Vs (circles) in both control and Hsc70-treated synapses. Asterisks mark postsynaptic spines. $\mathrm{C}=$ cisternae. Scale bars $=500 \mathrm{~nm}$. $\boldsymbol{C}$, $D, 3 D$ reconstructions further highlight the similarities and show that CCPs (yellow spheres) and CCVs (white spheres) are in normal numbers and clustered around the plasma membrane (green slabs; see insets). Active zone is shown in red. Scale bars $=500 \mathrm{~nm}$. $\boldsymbol{E}-\boldsymbol{M}$, There is little effect of exogenous $\mathrm{Hsc70}$ on clathrin-mediated synaptic vesicle endocytosis, as illustrated by normal number and distribution of SVs, PM evaginations, and CCPS/CCVs. Only the number of cisternae was greater, however, their size remains normal. Bars represent mean \pm SEM (per section, per synapse) from $n=27-28$ synapses, $n=2$ axons, $n=2$ animals/condition. Asterisk indicates significance $(p<0.05)$; n.s. $=$ not significant $(p>0.05)$ by Student's $t$ test $(\boldsymbol{E}, \boldsymbol{H}-\boldsymbol{K}, \boldsymbol{M})$ or ANOVA $(\boldsymbol{F}, \boldsymbol{G}, \boldsymbol{L})$.

synapses with Hsc70 puncta, and this did not occur after introduction of excess $\alpha$-synuclein into the axons (Fig. 6E; unstimulated control: $17.61 \pm 4.11 \%, n=85$ synapses, $n$ $=9$ axons; stimulated control: $62.06 \pm 7.49 \%, n=135$ synapses, $n=13$ axons; unstimulated $\alpha$-Syn: $29.39 \pm$ $8.76 \%, n=77$ synapses, $n=5$ axons; stimulated $\alpha$-Syn: $29.26 \pm 7.80 \%, n=76$ synapses, $n=6$ axons; ANOVA $p$ $<0.0005$; Tukey's post hoc). We also quantified the average number of Hsc70 puncta per synapse under the same conditions and obtained similar results. At control synapses, the average number of Hsc70 puncta per synapse increased on stimulation, but this did not occur after $\alpha$-synuclein treatment (Fig. 6F; unstimulated control: 0.19 \pm 0.05 puncta, $n=85$ synapses, $n=9$ axons; stimulated control: $0.84 \pm 0.14$ puncta, $n=135$ synapses, $n=13$ axons; unstimulated $\alpha$-Syn: $0.30 \pm 0.09$ puncta, $n=77$ synapses, $n=5$ axons; stimulated $\alpha$-Syn: $0.37 \pm 0.13$ puncta, $n=76$ synapses, $n=6$ axons; ANOVA $p=$
0.0012, Tukey's post hoc). In an independent set of experiments, using action potential stimulation $(20 \mathrm{~Hz}, 5 \mathrm{~min}$ as in the EM experiments) and a second Hsc70 antibody (Enzo SPA815 rat polyclonal), we observed similar results (Fig. 6G,H; \% synapses w/Hsc70 puncta: unstimulated control: $20.48 \pm 5.79 \%, n=34$ synapses, $n=3$ axons; stimulated control: $83.23 \pm 11.75 \%,=47$ synapses, $n=$ 3 axons; unstimulated $\alpha$-Syn: $40.74 \pm 11.75 \%, n=31$ synapses, $n=3$ axons; stimulated $\alpha$-Syn: $50.58 \pm$ $14.11 \%, n=43$ synapses, $n=4$ axons; ANOVA $p=0.03$; Tukey's post hoc; \#Hsc70 puncta/synapse: unstimulated control: $0.23 \pm 0.07 \%, n=34$ synapses, $n=3$ axons; stimulated control: $1.08 \pm 0.19 \%, n=47$ synapses, $n=$ 3 axons; unstimulated $\alpha$-Syn: $0.52 \pm 0.18 \%, n=31$ synapses, $n=3$ axons; stimulated $\alpha$-Syn: $0.63 \pm 0.23 \%$, $n=43$ synapses, $n=4$ axons; ANOVA $p=0.08$; Tukey's post hoc). Thus, excess $\alpha$-synuclein sequesters Hsc70 in vivo and reduces its availability at stimulated synapses, 
suggesting a possible mechanism underlying the CCV uncoating defects during synaptic vesicle recycling.

\section{Increasing Hsc70 ameliorates the $\alpha$-synuclein- induced vesicle trafficking defects}

The above results suggest that reduced availability of Hsc70 at synapses, and consequently its function, could underlie the $\alpha$-synuclein-induced defects in CCV uncoating and synaptic vesicle recycling. If so, then increasing Hsc70 levels would be expected to reverse the synaptic defects. To test this, we co-injected recombinant bovine Hsc70 (1-3 $\mu \mathrm{M}$ final) along with human $\alpha$-synuclein (7-13 $\mu \mathrm{M}$ final) and examined the effects at lamprey synapses. As a control for these experiments, we first injected Hsc70 alone (Fig. 7). As expected for an abundant chaperone protein under unperturbed conditions, Hsc70 had little effect on synaptic ultrastructure, and the synapses appeared normal (Fig. 7A-D). Quantification showed no effect on the synaptic vesicle clusters, plasma membrane, or the number or distribution of CCP/Vs (Fig. $7 E-H, K, L$; synaptic vesicles \%, control: $124.2 \pm 7.0 \mathrm{SVs} /$ section, $n$ $=27$ synapses, $n=2$ axons; Hsc70: $108.2 \pm 9.6$ SVs; $n$ $=28$ synapses, $n=2$ axons; Student's $t$ test; $p=0.18$; SV distribution, $<500 \mathrm{~nm}$, control: $79.91 \pm 3.12 \%$; Hsc70: $77.36 \pm 3.02 \%$; $>500 \mathrm{~nm}$, control: $20.09 \pm 3.12 \%$; Hsc70: $22.64 \pm 3.02 \% ; n=27-28$ synapses, $n=2$ axons; ANOVA $p<0.0001$; Tukey's post hoc $p=0.94$; plasma membrane, control: $2.61 \pm 0.12 \mu \mathrm{m}, n=27$ synapses, $n=2$ axons; Hsc70: $2.58 \pm 0.18 \mu \mathrm{m} ; n=28$ synapses, $n=2$ axons; Student's $t$ test; $p=0.89$; \#clathrin coats, control: $4.4 \pm 0.6$ coats, $n=27$ synapses, $n=$ 2 axons; Hsc70: $4.8 \pm 0.5$ coats, $n=28$ synapses, $n=2$ axons; Student's $t$ test; $p=0.60$; clathrin coat distribution, stage 1, control: $0.14 \pm 0.07 \mathrm{CCPs} /$ section; Hsc70: $0.15 \pm 0.07$ CCPs; stage 2, control: $0.36 \pm 0.12 \mathrm{CCPs}$, Hsc70: $0.15 \pm 0.07$ CCPs; stage 3, control: $2.39 \pm 0.47$ CCPs; Hsc70: $2.67 \pm 0.30$ CCPs; stage 4, control: $1.54 \pm$ 0.26 CCVs, Hsc70: $1.85 \pm 0.34$ CCVs; $n=27-28$ synapses, $n=2$ axons; ANOVA $p<0.0001$, Tukey's post hoc). The number of cisternae increased slightly, but their size remained unchanged (\#cisternae, control: $5.0 \pm 0.6$ cisternae, $n=27$ synapses, $n=2$ axons; Hsc70: $8.2 \pm$ 1.0 cisternae; $n=28$ synapses, $n=2$ axons; Student's $t$ test; $p=0.01$; size cisternae, control: $0.40 \pm 0.01 \mu \mathrm{m}, n$ $=141$ cisternae, $n=27$ synapses; Hsc70: $0.42 \pm 0.01$ $\mu \mathrm{m} ; n=221$ cisternae, $n=28$ synapses, $n=2$ axons; Student's $t$ test; $p=0.28)$. Thus, introducing Hsc70 alone produced very little effect on synaptic vesicle trafficking with no measurable effects on CME or synaptic vesicle clusters.

We next examined synapses co-treated with both $\alpha$-synuclein and Hsc70. As before, stimulated control synapses exhibited large vesicle clusters, shallow membrane evaginations, and few CCPs and CCVs (Fig. $8 A, C$ ). Compared to synapses treated with $\alpha$-synuclein alone, which exhibited dramatic CCV uncoating and synaptic vesicle recycling defects (Fig. 2), those co-treated with $\alpha$-synuclein and bovine Hsc70 appeared relatively normal with large synaptic vesicle clusters, and only a few cisternae, CCPs, and CCVs (Fig. 8B,D). 3D reconstructions revealed the remarkable extent to which Hsc70 ameliorated the $\alpha$-synuclein-associated synaptic vesicle trafficking defects (Fig. 8C,D). After introducing bovine Hsc70 along with human $\alpha$-synuclein, the CCPs and CCVs were now sparse and located near the plasma membrane, similar to their distribution at control synapses (Fig. 8C,D, insets). Quantitative analyses revealed no difference in the number of synaptic vesicles at synapses co-treated with Hsc70+ $\alpha$-synuclein versus controls (Fig. 8E; control: 105 \pm 11 SVs/section; Hsc70 $+\alpha$-Syn: $113 \pm 13$ SVs/section; $n=22-30$ synapses, $n=2$ axons; Students $t$ test; $p=$ $0.644)$. Although the SVs still appeared slightly dispersed (Fig. 8F), the percentages of vesicles near to $(<500 \mathrm{~nm})$ and far from $(>500 \mathrm{~nm})$ the active zone were no longer significantly different (Fig. 8G; $<500 \mathrm{~nm}$, control: $84.03 \pm$ 2.82\%; $\alpha$-Syn+Hsc70: $72.07 \pm 3.71 \%$; $>500 \mathrm{~nm}$, control: $15.97 \pm 2.82 \% ; \alpha$-Syn+Hsc70: $27.93 \pm 3.71 \% ; n=$ 20-28 synapses, $n=2$ axons/condition; ANOVA $p<$ 0.0001 ; Tukey's post hoc $p=0.09$ ). The synaptic vesicles were of similar size (diameter) in both conditions (control: $54.6 \pm 0.6 \mathrm{~nm}, n=200 \mathrm{SVs}, 10$ synapses; Hsc70 $+\alpha$-Syn: $52.9 \pm 0.8 \mathrm{~nm} ; n=200 \mathrm{SVs}, n=10$ synapses; Student's $t$ test; $p=0.07$ ). Similarly, the number and size of cisternae were unchanged (Fig. 8/,J; \#cisternae, control: $2.7 \pm$ 0.3 cisternae/section; Hsc70 $+\alpha$-Syn: $3.3 \pm 0.4$ cisternae/ section; $n=20-28$ synapses, $n=2$ axons; Student's $t$ test; $p=0.26$; size cisternae, control: $0.42 \pm 0.02 \mu \mathrm{m}$; Hsc70 $+\alpha$-Syn: $0.45 \pm 0.02 \mu \mathrm{m} ; n=53-91$ cisternae, $n=$ 20-28 synapses; Student's $t$ test; $p=0.34$ ). Hsc70 additionally restored the total number of clathrin-coated structures $(\mathrm{CCPs}+\mathrm{CCVs}$ ) to control levels (Fig. 8K; control: $2.1 \pm 0.3$ coats/section; Hsc70 $+\alpha$-Syn: $2.4 \pm 0.2$ coats/section; $n=20-28$ synapses, $n=2$ axons; Student's $t$ test; $p=0.35$ ). Furthermore, there was a complete rescue of the CCV uncoating defect (Fig. 8L; stage 1, control: $0.05 \pm 0.05$ CCPs; Hsc70 $+\alpha$-Syn: $0.07 \pm 0.05$ CCPs; stage 2, control: $0.40 \pm 0.11$ CCPs; $\mathrm{Hsc} 70+\alpha-$ Syn: $0.36 \pm 0.12$ CCPs; stage 3 , control $1.25 \pm 0.22$ CCPs, Hsc70+ $\alpha$-Syn: $1.25 \pm 0.20$ CCPs; stage 4, control: $0.35 \pm 0.11 \mathrm{CCVs}$, Hsc70 $+\alpha$-Syn: $0.68 \pm 0.14 \mathrm{CCVs}$; $n=20-28$ synapses; ANOVA $p=3.9 \times 10^{-12}$, Tukey's post hoc). Only the plasma membrane evaginations remained larger after Hsc70 and $\alpha$-synuclein co-injection, indicating some persistent effects on the plasma membrane (Fig. $8 H$; control: $1.95 \pm 0.15 \mu \mathrm{m} /$ section; Hsc70+ $\alpha$-Syn: $2.53 \pm 0.20 \mu \mathrm{m} ; n=22-30$ synapses; Student's $t$ test; $p=0.04$ ). The total membrane analysis further corroborated that synapses co-treated with Hsc70 and $\alpha$-synuclein were similar to controls (Fig. 8M; control $1.4 \pm 0.1 \mu \mathrm{m}^{2} ; \alpha$-Syn: $1.5 \pm 0.1 \mu \mathrm{m}^{2} ; n=20-28$ synapses, $n=2$ axons; Student's $t$ test; $p=0.70$ ). Thus, increasing exogenous Hsc70 levels largely reversed the synaptic vesicle trafficking defects caused by $\alpha$-synuclein, including the deficits in CCV uncoating.

\section{Discussion}

While a number of studies have focused on the physiologic roles of $\alpha$-synuclein at synapses (for review, see Sulzer and Edwards, 2019), the precise effects of excess $\alpha$-synuclein and the underlying mechanisms are less 

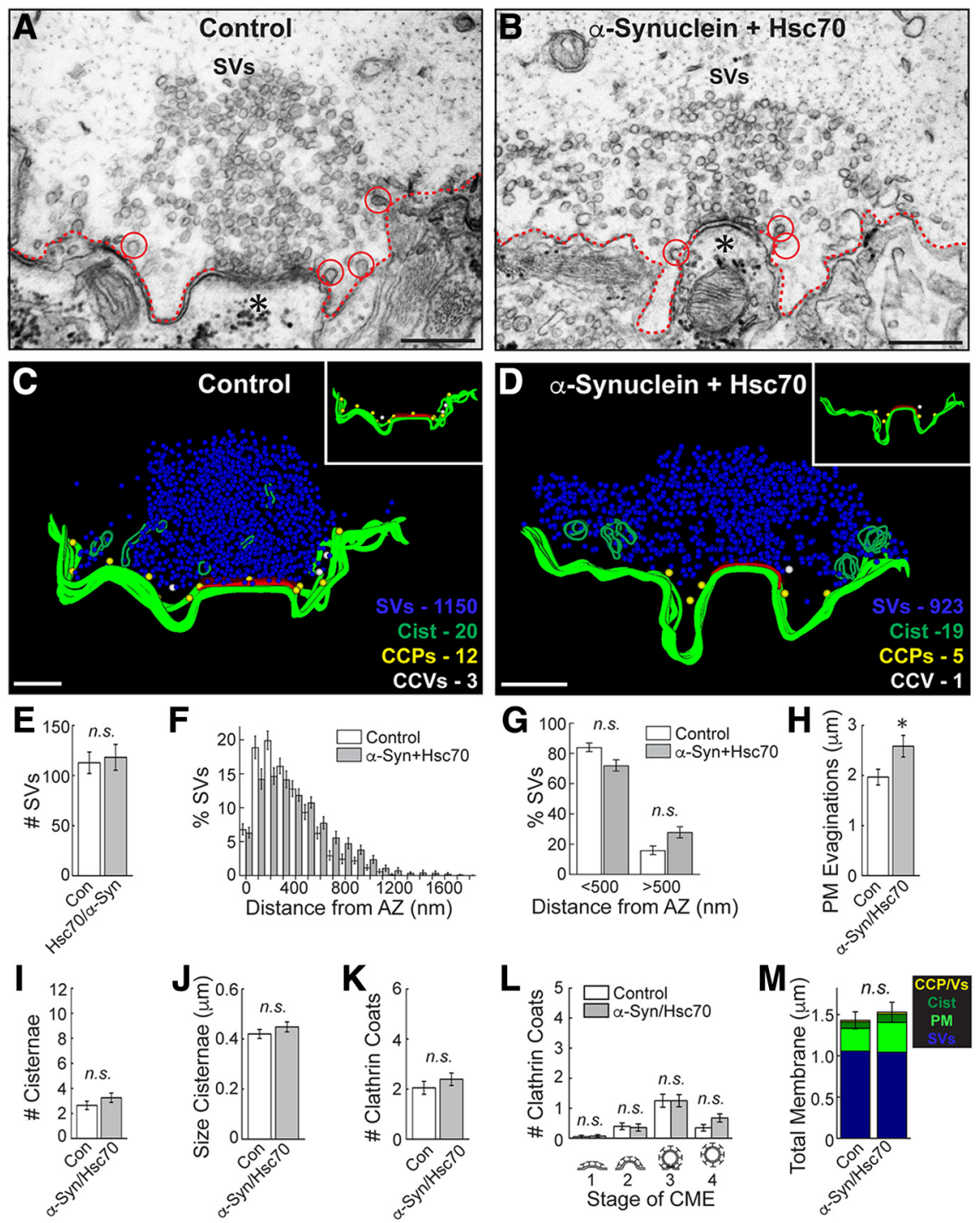

Figure 8. Increasing exogenous Hsc70 largely reverses the $\alpha$-synuclein-induced synaptic defects. $\boldsymbol{A}, \boldsymbol{B}$, Unlike synapses treated with $\alpha$-synuclein alone (Fig. 2), those co-treated with Hsc70 and $\alpha$-synuclein appear similar to control synapses, with large SV clusters and few cisternae or CCP/Ns (circles). C, D, 3D reconstructions reveal that synapses treated with Hsc70 and $\alpha$-synuclein appear normal. Insets show the distributions of CCPs (yellow spheres) and CCVs (white spheres), which are sparse and clustered around the plasma membrane (green slabs). Active zone is shown in red. $\boldsymbol{E}-\boldsymbol{M}$, The CCV uncoating and vesicle recycling defects caused by $\alpha$-synuclein were largely ameliorated by co-injection of Hsc70 as evidenced by normal numbers of SVs $(\boldsymbol{E})$, cisternae ( $\boldsymbol{J})$, and CCPs/CCVs $(\boldsymbol{K}-\boldsymbol{L})$. Only the PM evaginations were larger $(\boldsymbol{H})$. Notably, there was no longer any difference in the number of free CCVs after co-injection of Hsc70+ $\alpha$-synuclein, indicating a reversal of the uncoating defects $(\boldsymbol{L}$, stage 4$)$. Bars represent mean \pm SEM (per section, per synapse) from $n=22-30$ synapses, $n=2$ axons, $2 n=$ animals/condition. Asterisk indicates significance $(p<0.05)$; n.s. $=$ not significant $(p>0.05)$ by Student's $t$ test $(\boldsymbol{E}, \boldsymbol{H}-\boldsymbol{K}, \boldsymbol{M})$ or ANOVA $(\boldsymbol{F}-\boldsymbol{G}, \boldsymbol{L})$.

clear. Data presented here identify loss of Hsc70 availability at synapses, and consequently its function, as one mechanism by which excess $\alpha$-synuclein induces synaptic vesicle trafficking defects. Specifically, the sequestration of Hsc70 leads to an impairment of CCV uncoating at synapses, which consequently inhibits synaptic vesicle recycling. How might this work? A plausible explanation, shown in our working model, is that inhibiting CCV uncoating may trap clathrin and/or other limited coat proteins such as AP180 and AP2 within CCVs, making them unavailable for initiating subsequent rounds of endocytosis thereby leading to aberrant plasma membrane expan- sion and compensatory bulk endocytosis, resulting in formation of cisternae (Fig. 9A; Morgan et al., 1999, 2000; Walsh et al., 2018). Similarly, acute inactivation of CME in other models also resulted in a compensatory increase in atypical cisternae (Heerssen et al., 2008; Kasprowicz et al., 2008). In these respects, the phenotypes produced by excess $\alpha$-synuclein are suggestive of a pathologic gain of function. However, the plasma membrane expansion observed with excess $\alpha$-synuclein would also be consistent with direct effects of $\alpha$-synuclein accelerating vesicle fusion (Logan et al., 2017) and/or slowing early stages of clathrin-mediated synaptic vesicle endocytosis (Vargas 

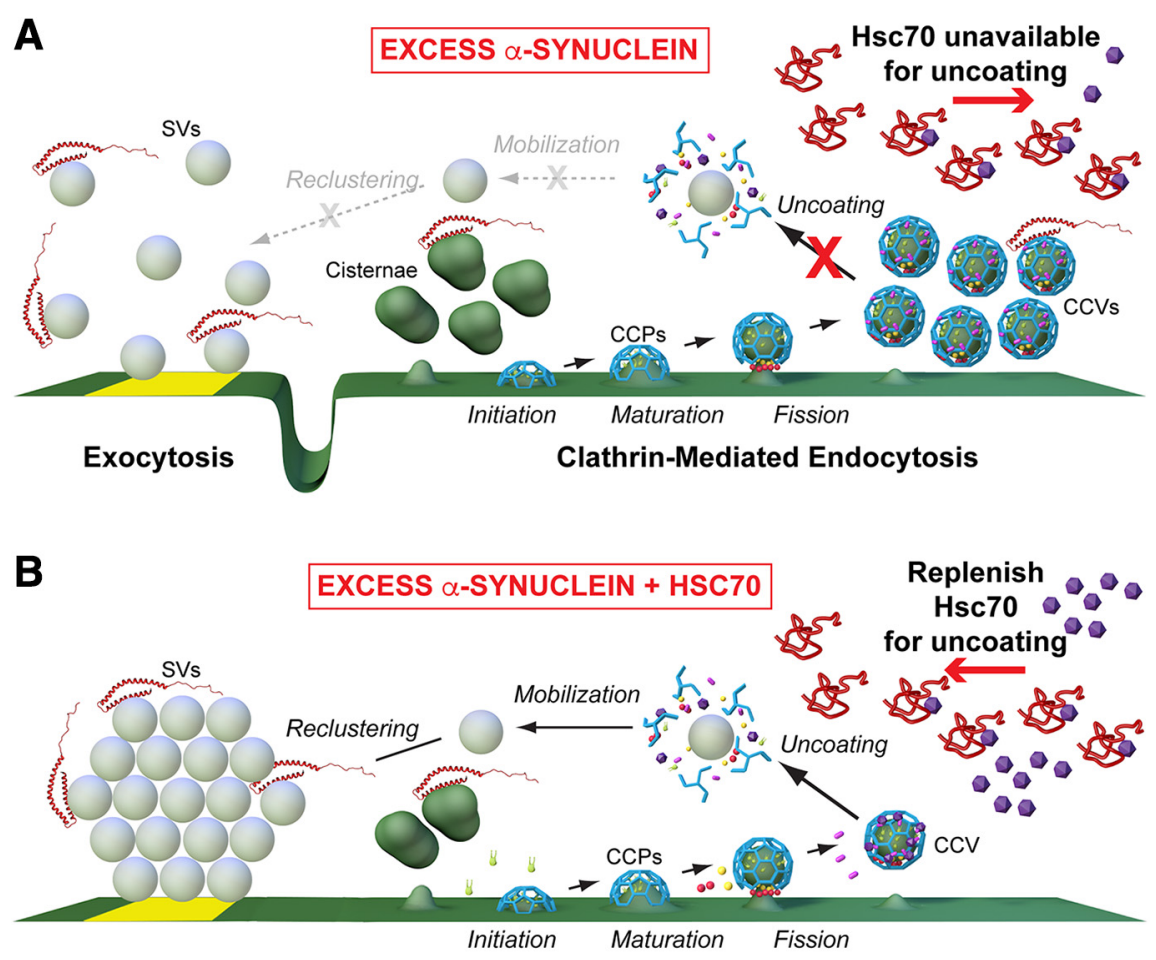

Exocytosis

Clathrin-Mediated Endocytosis

Figure 9. Working model for $\alpha$-synuclein-induced endocytic defects and amelioration by Hsc70. A, In the presence of excess $\alpha$-synuclein, endogenous Hsc70 becomes depleted at synapses, leading to impaired CCV uncoating and an inhibition of synaptic vesicle recycling. $\boldsymbol{B}$, Addition of exogenous Hsc70 restores CCV uncoating and leads to more normal synaptic vesicle recycling. (Graphics by Jack Cook and Tim Silva, Woods Hole Oceanographic Institution.)

et al., 2014), which is in line with our current understanding of its normal physiologic function. Similar to the $\alpha$-synuclein phenotype, impairments of CCV uncoating have also been observed at squid and mammalian synapses after directly perturbing Hsc70 recruitment to CCVs (Morgan et al., 2001; Leshchyns'ka et al., 2006). As with direct Hsc70 perturbations (Morgan et al., 2001), excess $\alpha$-synuclein also induced a loss of synaptic vesicles and expansion of the plasma membrane, indicating effects on vesicle recycling (Fig. 2; Busch et al., 2014; Medeiros et al., 2017).

By this working model, replenishing $\mathrm{Hsc} 70$ at synapses should have the effect of restoring CCV uncoating, thereby freeing clathrin and other limited coat proteins to recycle synaptic vesicles more efficiently (Fig. 9B). Indeed, when exogenous bovine Hsc70 was introduced along with human $\alpha$-synuclein, the CCV uncoating defects were completely rescued, and the synaptic vesicle clusters were restored to normal, indicating a significant improvement in synaptic vesicle recycling (Fig. 8). That the number and size of cisternae were also restored to control levels indicates their role in replenishing the vesicle cluster and suggests that they are affected by clathrin-dependent budding processes, although their identity remains unclear (e.g., recycling or bulk endosomes). The only morphologic deficits remaining after co-injection of $\alpha$-synuclein and $\mathrm{Hsc70}$ was an enlargement of the plasma membrane evaginations and a slight, but non-significant, dispersion of synaptic vesicles (Fig. 8). One possible ex- planation is that there may be a pool of $\alpha$-synuclein bound tightly to the plasma membrane and vesicles, which does not release in the presence of exogenous Hsc70 and therefore continues to slow endocytosis. While our data are consistent with the working model shown in Figure 9, we also acknowledge the possibility of an alternative explanation that $\alpha$-synuclein may inhibit vesicle recycling by some other undetermined mechanism, which is reversed by Hsc70 for example through its general chaperoning functions. Whatever the case, it is an exciting prospect that even substoichiometric amounts of Hsc70 can reverse the vast majority of the synaptic vesicle trafficking defects associated with excess $\alpha$-synuclein. It will be important in future experiments to determine if the remaining morphologic alterations can be further ameliorated by increasing the concentration of co-injected Hsc70 or by introducing Hsp110, which was recently shown to mitigate $\alpha$-synuclein pathology in mouse models (Taguchi et al., 2019) and is the most likely Hsc70 nucleotide exchange factor that regulates availability of free clathrin at synapses (Morgan et al., 2013).

Our results corroborate and extend previous reports of an interaction between $\alpha$-synuclein and Hsc70 (Pemberton et al., 2011; Redeker et al., 2012). Hsc70 binds both soluble and fibrillar $\alpha$-synuclein in the absence of nucleotides and inhibits fibril formation in vitro, leading to increased cell viability (Pemberton et al., 2011). Crosslinking studies using soluble $\alpha$-synuclein and Hsc70 indicated two discrete regions in $\alpha$-synuclein (a.a. $10-45$, 
97-102) that bind to multiple sites within the client binding domain of Hsc70, including several in the C-terminal region (Redeker et al., 2012). Similar binding sites were observed between $\alpha$-synuclein and the yeast Hsc70 ortholog, Ssa1p, indicating conservation of the interaction (Redeker et al., 2012). Our results further demonstrate conservation across synuclein orthologs (i.e., lamprey and human), which is due to the high degree of amino acid identity shared between their NTDs (Busch and Morgan, 2012). In the first Hsc70 binding region of $\alpha$-synuclein (a.a.10-45), lamprey $\gamma$-synuclein is $78 \%$ identical and $89 \%$ similar to human $\alpha$-synuclein (Busch et al., 2014). The second Hsc70 binding region (a.a. 97-102) is less conserved in lamprey $\gamma$-synuclein with only $30 \%$ similarity to human $\alpha$-synuclein, suggesting that the longer $\mathrm{N}$-terminal binding region (a.a. 10-45) is the stronger of the two binding regions. Wild-type $\alpha$-synuclein, A30P, and A53T all bound with equal efficacy to Hsc70 (Fig. 4) likely because the binding is distributed across the NTD region of $\alpha$-synuclein (Redeker et al., 2012). In contrast, binding of Hsc70 to E46K was reduced, perhaps because this mutation alters the charge distribution around the Hsc70 binding site. We also show that the C-terminal region of $\mathrm{Hsc70}$ is critical for mediating and/or stabilizing the interaction with $\alpha$-synuclein. The failure of $\mathrm{Hsc} 70 \Delta \mathrm{C}$ to bind $\alpha$-synuclein is consistent with observations that the region deleted in Hsc $70 \Delta \mathrm{C}$ includes residues that form part of the interface with $\alpha$-synuclein (Redeker et al., 2012). In addition, the deletion in Hsc70 $\Delta$ C destabilizes the terminal helix of $\mathrm{Hsc} 70 \mathrm{SBD}$, resulting in unwinding of this helix and cis-binding of its unfolded segment in the client binding site of nucleotide free Hsc70 (Morshauser et al., 1999; Jiang et al., 2005). The client binding site in Hsc70 also contributes to the interface with $\alpha$-synuclein (Redeker et al., 2012), and so cis-binding of this unfolded segment may compete with $\alpha$-synuclein binding. Going forward, it will be important to identify the most critical residues mediating the $\alpha$-synuclein/Hsc70 interaction to facilitate the design of reagents that disrupt this interaction, which might have therapeutic value for treatment of multiple diseases associated with $\alpha$-synuclein and/or clathrin uncoating defects.

Hsc70 was previously identified as a potential target in other $\alpha$-synuclein-related contexts. In human brains affected by PD, DLB, and related synucleinopathies, Hsc70 and other chaperone proteins are detected in high levels along with $\alpha$-synuclein (Auluck et al., 2002; Uryu et al., 2006). The co-occurrence of Hsc70 and $\alpha$-synuclein in Lewy bodies suggests an increased association of these proteins in disease states, which could deplete Hsc70 and impair its function in other cellular compartments. In support of this idea, $\alpha$-synuclein aggregation, fibrillation, trans-synaptic propagation, and neurotoxicity are reduced in the presence of Hsc70 or Hsp70 (Luk et al., 2008; Danzer et al., 2011; Pemberton et al., 2011). Furthermore, overexpression of Hsp70 reduced $\alpha$-synuclein aggregation and neuronal loss in Drosophila and mouse models of $\alpha$-synuclein toxicity (Auluck et al., 2002; Klucken et al., 2004). Thus, Hsc/p70-based reagents that can reverse misfolding and/or restore normal protein function have been suggested as potential therapeutic agents to reduce neurodegeneration caused by $\alpha$-synuclein (Dimant et al., 2012; Ebrahimi-Fakhari et al., 2013; Shorter, 2016). Our data extend the possible applications of such agents by showing that replenishing Hsc70 function may also be a viable strategy for improving the synapse-associated deficits observed in $\alpha$-synuclein-related disorders.

Importantly, our work also provides new insights into the cellular mechanisms for $\alpha$-synuclein and Hsc70 involvement in the neurodegenerative process, specifically related to the impacts on CME. Since CME is also involved more broadly in vesicle endocytosis from the plasma membrane and intracellular vesicle trafficking events, these experiments also have wider implications for potential impacts on membrane trafficking throughout the entire neuron. In addition, our work also highlights the need for the type of studies described here, in which the mechanism of phenotypic rescue is characterized in depth, because of the potential complexities of deploying a therapeutic approach that involves increasing the activity of a protein like Hsc70, which is involved in many cellular processes. We find that while Hsc70 fully rescues the CCV uncoating defects induced by $\alpha$-synuclein and restored the synaptic vesicle cluster, the membrane evaginations persisted, suggesting residual impairment of membrane endocytosis by $\alpha$-synuclein (Vargas et al., 2014). Such observations suggest not only the need to titrate such therapeutic approaches, but also to understand the mechanisms of phenotypic rescue so that any complications can be anticipated.

The findings reported here contribute to a growing body of evidence that PD and other forms of Parkinsonism may be linked to deficits in the clathrin-mediated synaptic vesicle recycling (Saez-Atienzar and Singleton, 2017), and an increasing number of findings are pointing toward specific impairments in the clathrin uncoating process. For example, many studies have now identified mutations or truncations in DNAJ, the gene that encodes for the Hsc70 co-chaperone, auxilin, in patients with juvenile Parkinsonism or early-onset PD (Edvardson et al., 2012; Köroğlu et al., 2013; Elsayed et al., 2016; Olgiati et al., 2016). In addition, auxilin was recently identified as a phosphorylation target of the PD-linked leucine-rich repeat kinase 2 (LRRK2) mutant R1441C, which led to impaired SV endocytosis and clathrin uncoating defects in patient-derived dopaminergic neurons (Nguyen and Krainc, 2018). Furthermore, GWAS studies have identified genetic variations and altered expression of GAK, the ubiquitously expressed version of neuronal-specific auxilin, among the top risk factors for familial PD across multiple populations worldwide (Pankratz et al., 2009; Tseng et al., 2013; Nagle et al., 2016). Several mutations in synaptojanin-1 have also been linked to early onset Parkinsonism (Krebs et al., 2013; Chen et al., 2015; Ben Romdhan et al., 2018). Transgenic mice carrying one of the synaptojanin-1 mutations (R258Q) in the Sac domain accumulated CCVs within their synapses and exhibited impaired synaptic vesicle recycling, as well as motor deficits and increased death (Cao et al., 2017). Thus, a growing body of evidence from both animal models and 
human genetics indicates that defects in $\mathrm{CME}$, and specifically in CCV uncoating, are at least susceptibility factors in PD and Parkinsonism, if not causal factors. Detection of mutations in auxilin that increase such susceptibility is especially notable because, unlike Hsc70 or other chaperones that have multiple cellular functions, auxilin's role appears to be limited to the single function of recruiting Hsc70 to CCVs to drive uncoating, so these observations strongly indicate that disruption of clathrin uncoating is a strong contributor to PD disease etiology. Thus, strategies that ensure proper CCV uncoating, for example by increasing $\mathrm{Hsc} 70$ availability or function, may hold promise for improving synaptic function and reducing neurodegeneration in PD and other $\alpha$-synucleinassociated diseases.

\section{References}

Antonny B, Burd C, De Camilli P, Chen E, Daumke O, Faelber K, Ford M, Frolov VA, Frost A, Hinshaw JE, Kirchhausen T, Kozlov MM, Lenz M, Low HH, McMahon H, Merrifield C, Pollard TD, Robinson PJ, Roux A, Schmid S (2016) Membrane fission by dynamin: what we know and what we need to know. EMBO J 35:2270-2284.

Atias M, Tevet Y, Sun J, Stavsky A, Tal S, Kahn J, Roy S, Gitler D (2019) Synapsins regulate $\alpha$-synuclein functions. Proc Natl Acad Sci USA 116:11116-11118.

Auluck PK, Chan HY, Trojanowski JQ, Lee VM, Bonini NM (2002) Chaperone suppression of alpha-synuclein toxicity in a Drosophila model for Parkinson's disease. Science 295:865-868.

Ben Romdhan S, Sakka S, Farhat N, Triki S, Dammak M, Mhiri C (2018) A novel SYNJ1 mutation in a Tunisian family with juvenile Parkinson's disease associated with epilepsy. J Mol Neurosci 66:273-278.

Bendor JT, Logan TP, Edwards RH (2013) The function of $\alpha$-synuclein. Neuron 79:1044-1066.

Bourne J, Morgan JR, Pieribone VA (2006) Actin polymerization regulates clathrin coat maturation during early stages of synaptic vesicle recycling at lamprey synapses. J Comp Neurol 497:600609.

Brodin L, Shupliakov O (2006) Giant reticulospinal synapse in lamprey: molecular links between active and periactive zones. Cell Tissue Res 326:301-310.

Buckley K, Kelly RB (1985) Identification of a transmembrane glycoprotein specific for secretory vesicles of neural and endocrine cells. J Cell Biol 100:1284-1294.

Burré J, Sharma M, Tsetsenis T, Buchman V, Etherton MR, Südhof TC (2010) Alpha-synuclein promotes SNARE-complex assembly in vivo and in vitro. Science 329:1663-1667.

Burré J, Sharma M, Südhof TC (2015) Definition of a molecular pathway mediating $\alpha$-synuclein neurotoxicity. J Neurosci 35:52215232.

Busch DJ, Morgan JR (2012) Synuclein accumulation is associated with cell-specific neuronal death after spinal cord injury. J Comp Neurol 520:1751-1771.

Busch DJ, Oliphint PA, Walsh RB, Banks SM, Woods WS, George JM, Morgan JR (2014) Acute increase of $\alpha$-synuclein inhibits synaptic vesicle recycling evoked during intense stimulation. Mol Biol Cell 25:3926-3941.

Cabin DE, Shimazu K, Murphy D, Cole NB, Gottschalk W, Mcllwain $\mathrm{KL}$, Orrison B, Chen A, Ellis CE, Paylor R, Lu B, Nussbaum RL (2002) Synaptic vesicle depletion correlates with attenuated synaptic responses to prolonged repetitive stimulation in mice lacking alpha-synuclein. J Neurosci 22:8797-8807.

Cao M, Wu Y, Ashrafi G, McCartney AJ, Wheeler H, Bushong EA, Boassa D, Ellisman MH, Ryan TA, De Camilli P (2017) Parkinson Sac domain mutation in Synaptojanin 1 impairs clathrin uncoating at synapses and triggers dystrophic changes in dopaminergic axons. Neuron 93:882-896.e5.
Chanaday NL, Cousin MA, Milosevic I, Watanabe S, Morgan J (2019) The synaptic vesicle cycle revisited: new insights into the modes and mechanisms. J Neurosci 39:8209-8216.

Chang-lleto B, Frere SG, Chan RB, Voronov SV, Roux A, Di Paolo G (2011) Synaptojanin 1-mediated PI(4,5)P2 hydrolysis is modulated by membrane curvature and facilitates membrane fission. Dev Cell 20:206-218.

Chen KH, Wu RM, Lin HI, Tai CH, Lin CH (2015) Mutational analysis of SYNJ1 gene (PARK20) in Parkinson's disease in a Taiwanese population. Neurobiol Aging 36:2905.e7-8.

Cookson MR, van der Brug M (2008) Cell systems and the toxic mechanism(s) of alpha-synuclein. Exp Neurol 209:5-11.

Cremona O, Di Paolo G, Wenk MR, Lüthi A, Kim WT, Takei K, Daniell L, Nemoto Y, Shears SB, Flavell RA, McCormick DA, De Camilli P (1999) Essential role of phosphoinositide metabolism in synaptic vesicle recycling. Cell 99:179-188.

Danzer KM, Ruf WP, Putcha P, Joyner D, Hashimoto T, Glabe C, Hyman BT, McLean PJ (2011) Heat-shock protein 70 modulates toxic extracellular $\alpha$-synuclein oligomers and rescues transsynaptic toxicity. FASEB J 25:326-336.

Davidson WS, Jonas A, Clayton DF, George JM (1998) Stabilization of alpha-synuclein secondary structure upon binding to synthetic membranes. J Biol Chem 273:9443-9449.

Dimant H, Ebrahimi-Fakhari D, McLean PJ (2012) Molecular chaperones and co-chaperones in Parkinson disease. Neuroscientist 18:589-601.

Ebrahimi-Fakhari D, Saidi LJ, Wahlster L (2013) Molecular chaperones and protein folding as therapeutic targets in Parkinson's disease and other synucleinopathies. Acta Neuropathol Commun $1: 79$

Edvardson S, Cinnamon Y, Ta-Shma A, Shaag A, Yim YI, Zenvirt S, Jalas C, Lesage S, Brice A, Taraboulos A, Kaestner KH, Greene LE, Elpeleg O (2012) A deleterious mutation in DNAJC6 encoding the neuronal-specific clathrin-uncoating co-chaperone auxilin, is associated with juvenile parkinsonism. PLoS One 7:e36458.

Eguchi K, Taoufiq Z, Thorn-Seshold O, Trauner D, Hasegawa M, Takahashi T (2017) Wild-type monomeric $\alpha$-synuclein can impair vesicle endocytosis and synaptic fidelity via tubulin polymerization at the calyx of held. J Neurosci 37:6043-6052.

Elsayed LE, Drouet V, Usenko T, Mohammed IN, Hamed AA, Elseed MA, Salih MA, Koko ME, Mohamed AY, Siddig RA, Elbashir MI, Ibrahim ME, Durr A, Stevanin G, Lesage S, Ahmed AE, Brice A (2016) A novel nonsense mutation in DNAJC6 expands the phenotype of autosomal-recessive juvenile-onset Parkinson's disease. Ann Neurol 79:335-337.

Evergren E, Marcucci M, Tomilin N, Löw P, Slepnev V, Andersson F, Gad H, Brodin L, De Camilli P, Shupliakov O (2004) Amphiphysin is a component of clathrin coats formed during synaptic vesicle recycling at the lamprey giant synapse. Traffic 5:514-528.

Evergren E, Zotova E, Brodin L, Shupliakov O (2006) Differential efficiency of the endocytic machinery in tonic and phasic synapses. Neuroscience 141:123-131.

Farsi Z, Gowrisankaran S, Krunic M, Rammner B, Woehler A, Lafer EM, Mim C, Jahn R, Milosevic I (2018) Clathrin coat controls synaptic vesicle acidification by blocking vacuolar ATPase activity. Elife 7:e32569

Fiala JC (2005) Reconstruct: a free editor for serial section microscopy. J Microsc 218:52-61.

Flaherty KM, DeLuca-Flaherty C, McKay DB (1990) Threedimensional structure of the ATPase fragment of a 70K heat-shock cognate protein. Nature 346:623-628.

Fortin DL, Nemani VM, Voglmaier SM, Anthony MD, Ryan TA, Edwards $\mathrm{RH}$ (2005) Neural activity controls the synaptic accumulation of alpha-synuclein. J Neurosci 25:10913-10921.

Gan Q, Watanabe S (2018) Synaptic vesicle endocytosis in different model systems. Front Cell Neurosci 12:171.

Granseth B, Odermatt B, Royle SJ, Lagnado L (2006) Clathrinmediated endocytosis is the dominant mechanism of vesicle retrieval at hippocampal synapses. Neuron 51:773-786. 
Greten-Harrison B, Polydoro M, Morimoto-Tomita M, Diao L, Williams AM, Nie EH, Makani S, Tian N, Castillo PE, Buchman VL, Chandra SS (2010) $\alpha \beta \gamma$-Synuclein triple knockout mice reveal age-dependent neuronal dysfunction. Proc Natl Acad Sci USA 107:19573-19578.

Heerssen H, Fetter RD, Davis GW (2008) Clathrin dependence of synaptic-vesicle formation at the Drosophila neuromuscular junction. Curr Biol 18:401-409.

Heuser JE, Reese TS (1973) Evidence for recycling of synaptic vesicle membrane during transmitter release at the frog neuromuscular junction. J Cell Biol 57:315-344.

Ingelsson M (2016) Alpha-synuclein oligomers-neurotoxic molecules in Parkinson's disease and other Lewy body disorders. Front Neurosci 10:408.

Jiang J, Prasad K, Lafer EM, Sousa R (2005) Structural basis of interdomain communication in the Hsc70 chaperone. Mol Cell 20:513-524.

Kasprowicz J, Kuenen S, Miskiewicz K, Habets RL, Smitz L, Verstreken P (2008) Inactivation of clathrin heavy chain inhibits synaptic recycling but allows bulk membrane uptake. J Cell Biol 182:1007-1016.

Keen JH, Willingham MC, Pastan IH (1979) Clathrin-coated vesicles: isolation, dissociation and factor-dependent reassociation of clathrin baskets. Cell 16:303-312.

Klucken J, Shin Y, Masliah E, Hyman BT, McLean PJ (2004) Hsp70 reduces alpha-synuclein aggregation and toxicity. $\mathrm{J}$ Biol Chem 279:25497-25502.

Köroğlu Ç, Baysal L, Cetinkaya M, Karasoy H, Tolun A (2013) DNAJC6 is responsible for juvenile parkinsonism with phenotypic variability. Parkinsonism Relat Disord 19:320-324.

Kramer ML, Schulz-Schaeffer WJ (2007) Presynaptic $\alpha$-synuclein aggregates, not Lewy bodies, cause neurodegeneration in dementia with Lewy bodies. J Neurosci 27:1405-1410.

Krebs CE, Karkheiran S, Powell JC, Cao M, Makarov V, Darvish H, Di Paolo G, Walker RH, Shahidi GA, Buxbaum JD, De Camilli P, Yue Z, Paisán-Ruiz C (2013) The Sac1 domain of SYNJ1 identified mutated in a family with early-onset progressive Parkinsonism with generalized seizures. Hum Mutat 34:1200-1207.

Lee VM, Trojanowski JQ (2006) Mechanisms of Parkinson's disease linked to pathological alpha-synuclein: new targets for drug discovery. Neuron 52:33-38.

Leshchyns'ka I, Sytnyk V, Richter M, Andreyeva A, Puchkov D, Schachner M (2006) The adhesion molecule CHL1 regulates uncoating of clathrin-coated synaptic vesicles. Neuron 52:10111025.

Logan T, Bendor J, Toupin C, Thorn K, Edwards RH (2017) $\alpha$-Synuclein promotes dilation of the exocytotic fusion pore. Nat Neurosci 20:681-689.

Luk KC, Mills IP, Trojanowski JQ, Lee VM (2008) Interactions between Hsp70 and the hydrophobic core of alpha-synuclein inhibit fibril assembly. Biochemistry 47:12614-12625.

Maroteaux L, Campanelli JT, Scheller RH (1988) Synuclein: a neuronspecific protein localized to the nucleus and presynaptic nerve terminal. J Neurosci 8:2804-2815.

Medeiros AT, Soll LG, Tessari I, Bubacco L, Morgan JR (2017) $\alpha$-Synuclein dimers impair vesicle fission during clathrin-mediated synaptic vesicle recycling. Front Cell Neurosci 11:388.

Medeiros AT, Bubacco L, Morgan JR (2018) Impacts of increased $\alpha$-synuclein on clathrin-mediated endocytosis at synapses: implications for neurodegenerative diseases. Neural Regen Res 13: 647-648.

Miller DW, Hague SM, Clarimon J, Baptista M, Gwinn-Hardy K, Cookson MR, Singleton AB (2004) Alpha-synuclein in blood and brain from familial Parkinson disease with SNCA locus triplication. Neurology 62:1835-1838.

Morgan JR, Zhao X, Womack M, Prasad K, Augustine GJ, Lafer EM (1999) A role for the clathrin assembly domain of AP180 in synaptic vesicle endocytosis. J Neurosci 19:10201-10212.
Morgan JR, Prasad K, Hao W, Augustine GJ, Lafer EM (2000) A conserved clathrin assembly motif essential for synaptic vesicle endocytosis. J Neurosci 20:8667-8676.

Morgan JR, Prasad K, Jin S, Augustine GJ, Lafer EM (2001) Uncoating of clathrin-coated vesicles in presynaptic terminals: roles for Hsc70 and auxilin. Neuron 32:289-300.

Morgan JR, Di Paolo G, Werner H, Shchedrina VA, Pypaert M, Pieribone VA, De Camilli $P$ (2004) A role for talin in presynaptic function. J Cell Biol 167:43-50.

Morgan JR, Jiang J, Oliphint PA, Jin S, Gimenez LE, Busch DJ, Foldes AE, Zhuo Y, Sousa R, Lafer EM (2013) A role for an Hsp70 nucleotide exchange factor in the regulation of synaptic vesicle endocytosis. J Neurosci 33:8009-8021.

Morshauser RC, Hu W, Wang H, Pang Y, Flynn GC, Zuiderweg ER (1999) High-resolution solution structure of the $18 \mathrm{kDa}$ substratebinding domain of the mammalian chaperone protein Hsc70. J Mol Biol 289:1387-1403.

Nagle MW, Latourelle JC, Labadorf A, Dumitriu A, Hadzi TC, Beach TG, Myers RH (2016) The 4p16.3 Parkinson disease risk locus is associated with GAK expression and genes involved with the synaptic vesicle membrane. PLoS One 11:e0160925.

Nandi PK, Irace G, Van Jaarsveld PP, Lippoldt RE, Edelhoch H (1982) Instability of coated vesicles in concentrated sucrose solutions. Proc Natl Acad Sci USA 79:5881-5885.

Nemani VM, Lu W, Berge V, Nakamura K, Onoa B, Lee MK, Chaudhry FA, Nicoll RA, Edwards RH (2010) Increased expression of alpha-synuclein reduces neurotransmitter release by inhibiting synaptic vesicle reclustering after endocytosis. Neuron 65:66-79.

Nguyen M, Krainc D (2018) LRRK2 phosphorylation of auxilin mediates synaptic defects in dopaminergic neurons from patients with Parkinson's disease. Proc Natl Acad Sci USA 115:5576-5581.

Olgiati S, Quadri M, Fang M, Rood JP, Saute JA, Chien HF, Bouwkamp CG, Graafland J, Minneboo M, Breedveld GJ, Zhang J; International Parkinsonism Genetics Network, Verheijen FW, Boon AJ, Kievit AJ, Jardim LB, Mandemakers W, Barbosa ER, Rieder CR, Leenders KL, et al. (2016) DNAJC6 mutations associated with early-onset Parkinson's disease. Ann Neurol 79:244-256.

Pankratz N, Wilk JB, Latourelle JC, DeStefano AL, Halter C, Pugh EW, Doheny KF, Gusella JF, Nichols WC, Foroud T, Myers RH; PSG-PROGENI and GenePD Investigators, Coordinators and Molecular Genetic Laboratories (2009) Genomewide association study for susceptibility genes contributing to familial Parkinson disease. Hum Genet 124:593-605.

Pemberton S, Madiona K, Pieri L, Kabani M, Bousset L, Melki R (2011) Hsc70 protein interaction with soluble and fibrillar alphasynuclein. J Biol Chem 286:34690-34699.

Redeker V, Pemberton S, Bienvenut W, Bousset L, Melki R (2012) Identification of protein interfaces between $\alpha$-synuclein, the principal component of Lewy bodies in Parkinson disease, and the molecular chaperones human Hsc70 and the yeast Ssa1p. J Biol Chem 287:32630-32639.

Saez-Atienzar S, Singleton AB (2017) Parkinson disease and clathrin coat dynamics at synapses, why not? Mov Disord 32:1163.

Saheki Y, De Camilli P (2012) Synaptic vesicle endocytosis. Cold Spring Harb Perspect Biol 4:a005645.

Schulz-Schaeffer WJ (2010) The synaptic pathology of alphasynuclein aggregation in dementia with Lewy bodies, Parkinson's disease and Parkinson's disease dementia. Acta Neuropathol 120: 131-143.

Scott DA, Tabarean I, Tang Y, Cartier A, Masliah E, Roy S (2010) A pathologic cascade leading to synaptic dysfunction in alphasynuclein-induced neurodegeneration. J Neurosci 30:8083-8095.

Shorter J (2016) Engineering therapeutic protein disaggregases. Mol Biol Cell 27:1556-1560.

Shupliakov O, Bloom OE, Gustafsson JS, Kjaerulff O, Low P, Tomilin N, Pieribone VA, Greengard P, Brodin L (2002) Impaired recycling of synaptic vesicles after acute perturbation of the presynaptic actin cytoskeleton. Proc Natl Acad Sci U S A 99:14476-14481.

Singleton AB, Farrer M, Johnson J, Singleton A, Hague S, Kachergus J, Hulihan M, Peuralinna T, Dutra A, Nussbaum R, Lincoln S, Crawley A, 
Hanson M, Maraganore D, Adler C, Cookson MR, Muenter M, Baptista M, Miller D, Blancato J, et al. (2003) Alpha-synuclein locus triplication causes Parkinson's disease. Science 302:841.

Sousa R, Liao HS, Cuellar J, Jin S, Valpuesta JM, Jin AJ, Lafer EM (2016) Clathrin-coat disassembly illuminates the mechanisms of Hsp70 force generation. Nat Struct Mol Biol 23:821-829.

Spinelli KJ, Taylor JK, Osterberg VR, Churchill MJ, Pollock E, Moore C, Meshul CK, Unni VK (2014) Presynaptic alpha-synuclein aggregation in a mouse model of Parkinson's disease. J Neurosci 34:2037-2050.

Sulzer D, Edwards RH (2019) The physiological role of $\alpha$-synuclein and its relationship to Parkinson's Disease. J Neurochem 150: 475-486.

Sun J, Wang L, Bao H, Premi S, Das U, Chapman ER, Roy S (2019) Functional cooperation of $\alpha$-synuclein and VAMP2 in synaptic vesicle recycling. Proc Natl Acad Sci USA 116:11113-11115.

Taguchi Y, Gorenberg EL, Nagy M, Thrasher D, Fenton WA, Volpicelli-Daley L, Horwich AL, Chandra SS (2019) Hsp110 mitigates $\alpha$-synuclein pathology in vivo. Proc Natl Acad Sci USA 116:24310-24316.

Takei K, McPherson PS, Schmid SL, De Camilli P (1995) Tubular membrane invaginations coated by dynamin rings are induced by GTP-gamma $S$ in nerve terminals. Nature 374:186-190.

Tseng WE, Chen CM, Chen YC, Yi Z, Tan EK, Wu YR (2013) Genetic variations of GAK in two Chinese Parkinson's disease populations: a case-control study. PLoS One 8:e67506.

Ungewickell E, Ungewickell H, Holstein SE, Lindner R, Prasad K, Barouch W, Martin B, Greene LE, Eisenberg E (1995) Role of auxilin in uncoating clathrin-coated vesicles. Nature 378:632-635.

Uryu K, Richter-Landsberg C, Welch W, Sun E, Goldbaum O, Norris EH, Pham CT, Yazawa I, Hilburger K, Micsenyi M, Giasson BI, Bonini NM, Lee VM, Trojanowski JQ (2006) Convergence of heat shock protein 90 with ubiquitin in filamentous alpha-synuclein inclusions of alpha-synucleinopathies. Am J Pathol 168:947-961.

Vargas KJ, Makani S, Davis T, Westphal CH, Castillo PE, Chandra SS (2014) Synucleins regulate the kinetics of synaptic vesicle endocytosis. J Neurosci 34:9364-9376.
Volpicelli-Daley LA, Luk KC, Patel TP, Tanik SA, Riddle DM, Stieber A, Meaney DF, Trojanowski JQ, Lee VM (2011) Exogenous $\alpha$-synuclein fibrils induce Lewy body pathology leading to synaptic dysfunction and neuron death. Neuron 72:57-71.

Walsh RB, Bloom OE, Morgan JR (2018) Acute manipulations of clathrin-mediated endocytosis at presynaptic nerve terminals. Methods Mol Biol 1847:65-82.

Wang L, Das U, Scott DA, Tang Y, McLean PJ, Roy S (2014) $\alpha$-Synuclein multimers cluster synaptic vesicles and attenuate recycling. Curr Biol 24:2319-2326.

Watanabe S, Trimbuch T, Camacho-Perez M, Rost BR, Brokowski B, Sohl-Kielczynski B, Felies A, Davis MW, Rosenmund C, Jorgensen EM (2014) Clathrin regenerates synaptic vesicles from endosomes. Nature 515:228-233.

Westphal CH, Chandra SS (2013) Monomeric synucleins generate membrane curvature. J Biol Chem 288:1829-1840.

Wickelgren WO, Leonard JP, Grimes MJ, Clark RD (1985) Ultrastructural correlates of transmitter release in presynaptic areas of lamprey reticulospinal axons. J Neurosci 5:1188-1201.

Wilbanks SM, Chen L, Tsuruta H, Hodgson KO, McKay DB (1995) Solution small-angle $X$-ray scattering study of the molecular chaperone Hsc70 and its subfragments. Biochemistry 34:1209512106.

Wilhelm BG, Mandad S, Truckenbrodt S, Krohnert K, Schafer C, Rammner B, Koo SJ, Classen GA, Krauss M, Haucke V, Urlaub H, Rizzoli SO (2014) Composition of isolated synaptic boutons reveals the amounts of vesicle trafficking proteins. Science 344: 1023-1028.

Xu J, Wu XS, Sheng J, Zhang Z, Yue HY, Sun L, Sgobio C, Lin X, Peng S, Jin Y, Gan L, Cai H, Wu LG (2016) $\alpha$-Synuclein mutation inhibits endocytosis at mammalian central nerve terminals. J Neurosci 36:4408-4414.

Zhang Y, Zuiderweg ER (2004) The 70-kDa heat shock protein chaperone nucleotide-binding domain in solution unveiled as a molecular machine that can reorient its functional subdomains. Proc Natl Acad Sci USA 101:10272-10277. 